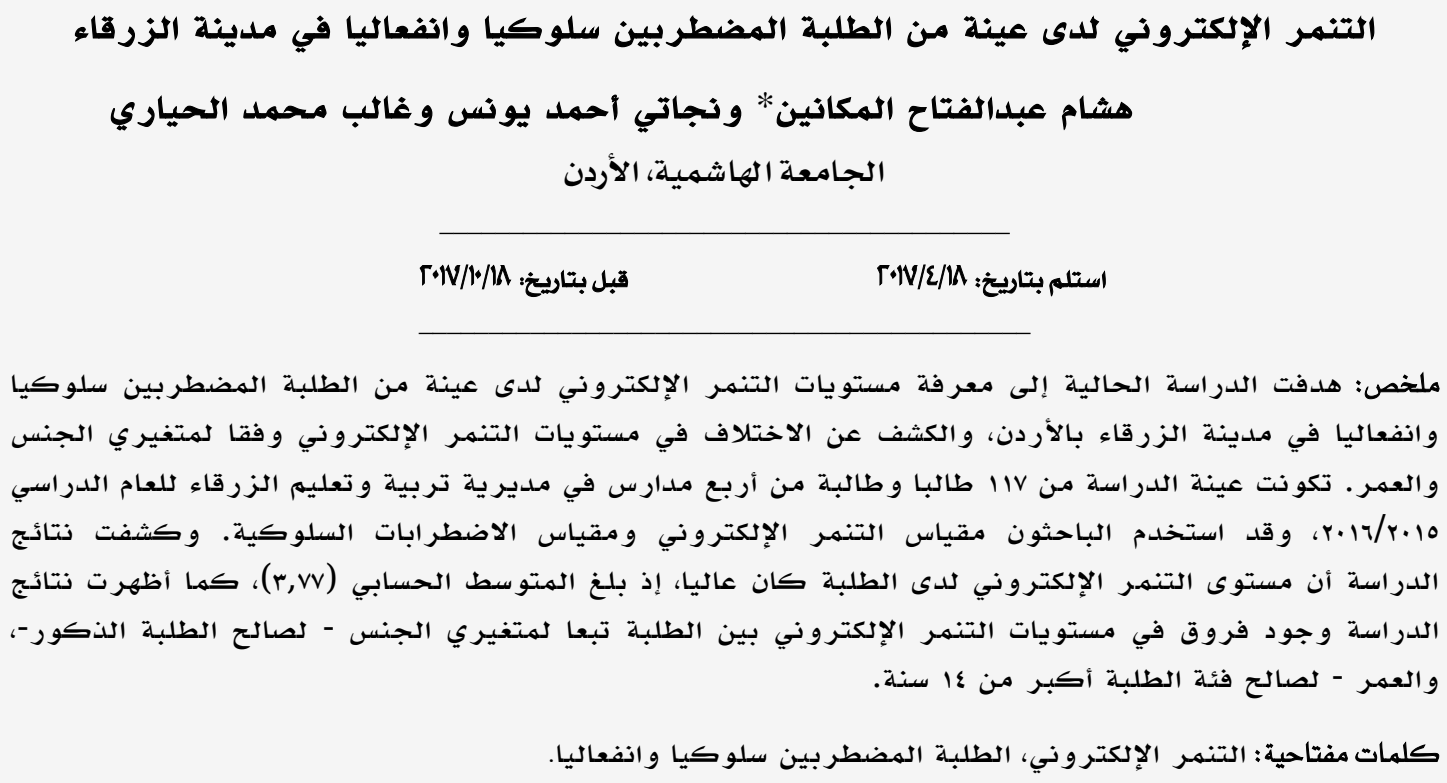

\title{
Electronic Bullying among a Sample of Students with Emotional and Behavioral Disorders in Zarqa City
}

\section{Hisham A. Almakanin,* Najati A. Younis, \& Ghaleb M. Alhiary}

The Hashemite University, Jordan

\begin{abstract}
The current study aimed at investigating levels of electronic bullying among a sample of students with emotional and behavioral disorders in the city of Zarqa, Jordan. Further, the study aimed at investigating the existence of any differences in levels of bullying due to gender and age. The sample consisted of 117 male and female students recruited from 4 public schools in Zarqa educational district in academic year 2015/2016. The Electronic Bullying Scale and Behavioral Disorder Scale were used. The results indicated high levels of electronic bullying among students, with a mean of 3.77 out of 4 . Additionally, statisticaly significant differences were found between male and female students -in favor of male students- and across age -in favor of students older than 14 years.
\end{abstract}

Keywords: Electronic bullying, students with emotional and behavioral disorders.

*makaneen@hu.edu.jo 
الديار (Y.|r) إلى أن التنهمر يتضهمن عناصر

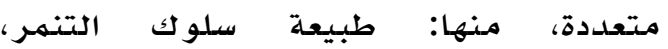

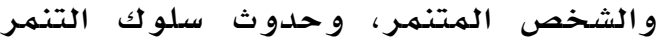
و تكر اره عن قصد بشكل منتظم و وخفي، و عدم توازن القوة بين المتنهمر والضحية، و إلحاق

الأذى و الألم النفسي و الجسدي بهون بالضحية. لقد ازداد اهتهام الباحثين بظاهرة التتـمر

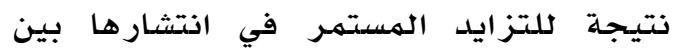
الطلبة، وخطورة آثارها على الطلبـة، ففي أستراليا يتعرض طالب من بين ستة طلاب

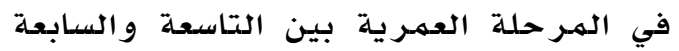

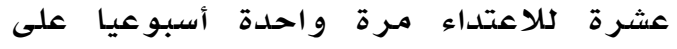

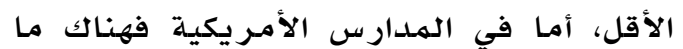

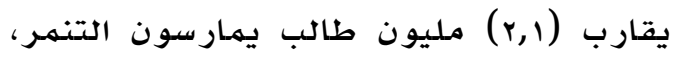

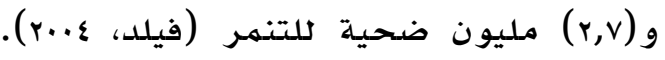
Liang, Flisher \& ) كما أشارت نتائج دراسة

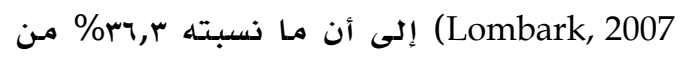
طلبة المدارس في جنوب إفريقيا منخرطين إنسية

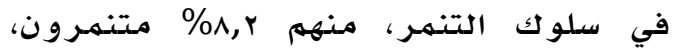

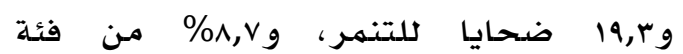

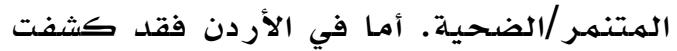

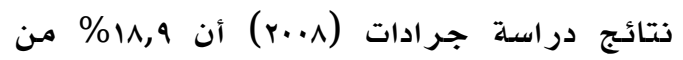
طلبة المدارس الأساسية قد صنفوا على أنهم

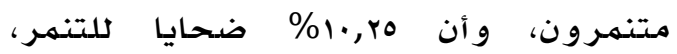

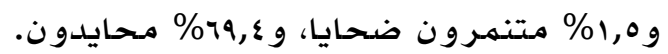
كما جلب التطور التكنو لوجي تهديدات غير

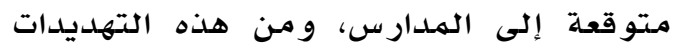

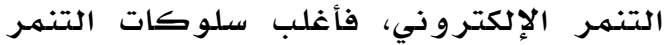

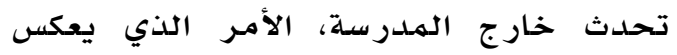

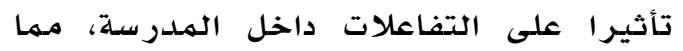
يضع المدارس في تحديات لمواجهة التتهمر

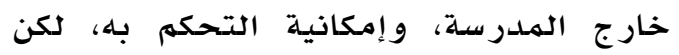
التـهمر الإلكتروني هو تهديد مهتد من البيت

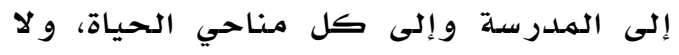

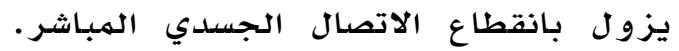

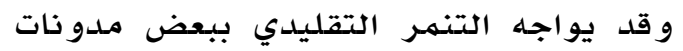

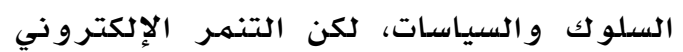

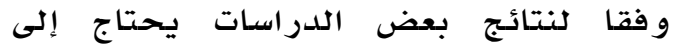

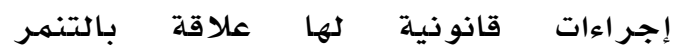

للتفاعلات والعلاقات بين الطلبة داخل الملدرسلة وخارجها أشكال متعددة؛ يترك

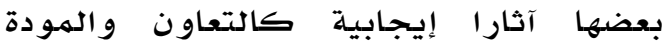
و التعاطف و العلاقات الحميمهة، و بعضها الآخر يترك آثارا سلبية كالعدوان، والضرب، و الشتم، والاستهزاء، والإهانة. و وتتميز هذانه

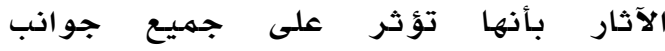
الشخصية الإنسانية النفسية، والانفعالية،

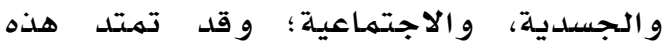

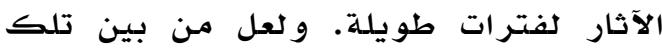

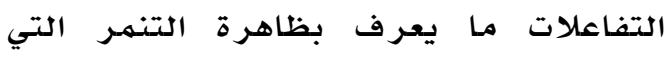
أصبـحت مس المشكلات التربوية ذات الآثار السلبية الخطيرة على طلبة الهمدارس، ومهما يزيد من خطورة هذه الظاهرة أنها في تزايد مستمـر في البيئات المدررسية، ووتتزايد آثارها

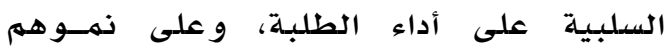

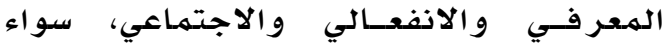

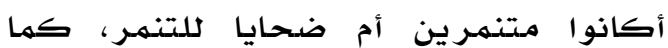

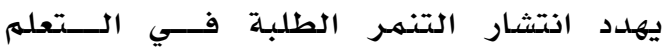
ضمن بيئة صـفية آمنــة (أبو غزال، و..r).

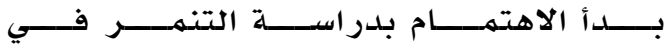
الســبعينيات مــن القــرن المـاضــي، و أصــبـح

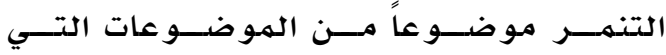
تحظـى بـاهتهــام متز ايــد فــي العديـــد مــن

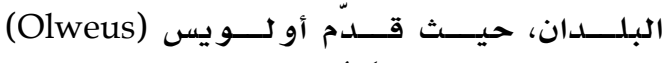

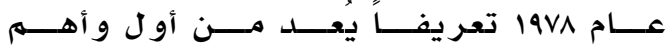

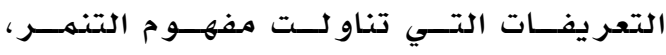

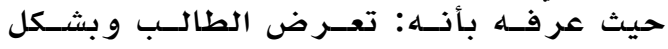

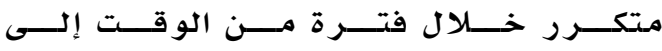

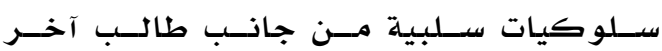
أو أكثر (و اكد، 10. r).

ويعرف جرادات التنمر بأنه: قيام الطالب بسلوكات سلبية بشكل متعمد ومتكرر خلمرل فترة من الوقت ضد طادب آخر أو أكثر من

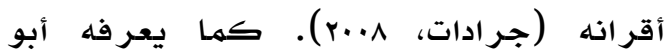

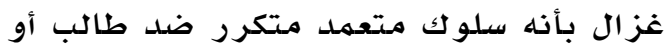
أكثر يتضمن الإيذاء الجسدي أو اللفظي أو أولاء

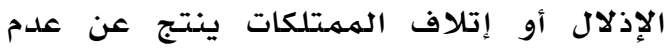

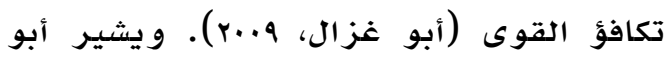


2007) إلى أن ما نسبته \%§\% من الطلبة كبيري السن قد تم التنهمر عليهم خلاسل تواجدهم على الانتر نت. وأن هذه النسبـة قد آدم

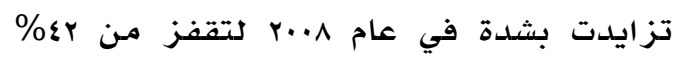

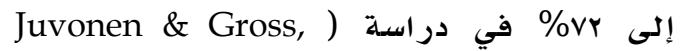

(2008

و يعرف بفي و ديان (Buffy \& Dianne, 2009)

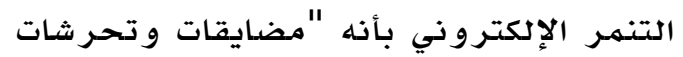
عن بعد باستخدام وسائل الاتصال الإلكترو ني الإني

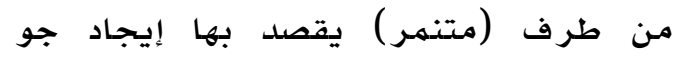

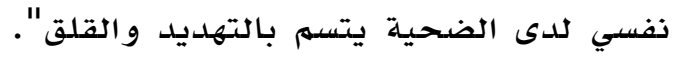

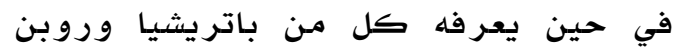

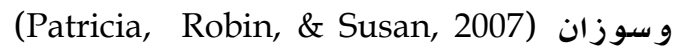
بأنه أية مضايقة مقصودة تحدث من طرف راث

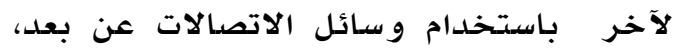
و يعرفه كل من ترولي وهانل و وشيلدز بأنه (Trolley, Hanel \& Shields, 2006)

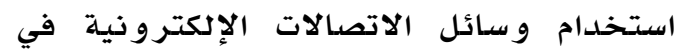
إيقاع أذى مقصود بطرف آخر دون الاتصدال الجسسي المباشر به.

ويتميز التنهمر الإنكتروني عن التنمر

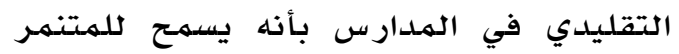

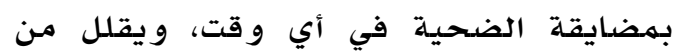

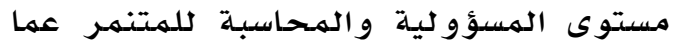
هو عليه الحال في التتهمر وجها لوجه، كهما

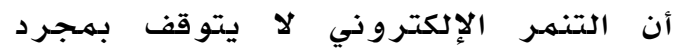

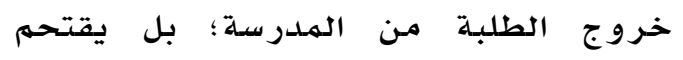

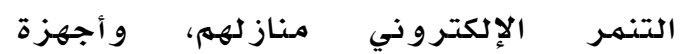

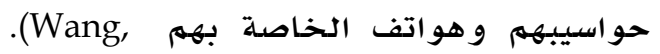
Lannotti \& Nansel, 2009; Kowalski, كما تمكن الوسائل الهتاحة Limber, 2007)

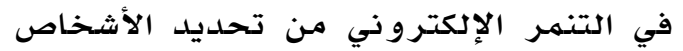

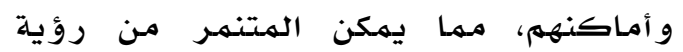

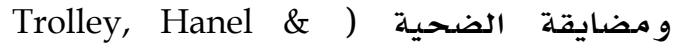
.(Shields, 2006

Hinduja \& ) ويشير هندوجا وباتشين (Patchin, 2008

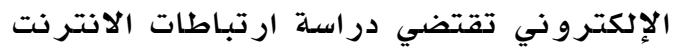

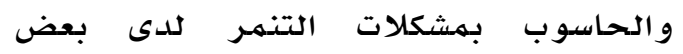

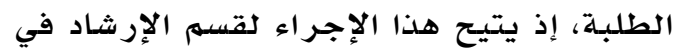

الإنكترو ني، ووضع سياسـات خاصدة به تحديدا .(Buffy \& Dianne, 2009)

و يؤكد ( Schneider, O'Donnell, Stueve \& (Coulter, 2012 بين الطلبـة، وخصوصا مهن وقعوا ضحايا للتنهمر الإلكتروني، كمها ارتفعت نسب آثار

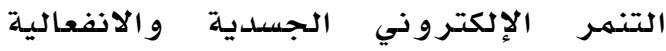

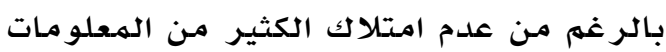

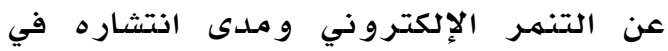

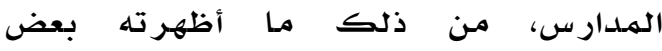

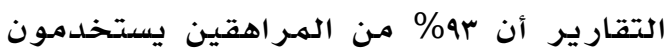

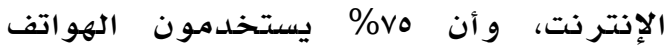

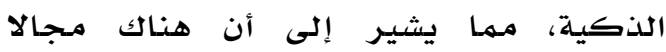
كبيرا للتنهمر الإلكتروني بينههم، وأن تفشيه في المدارس سريع جدا، فقد أكد لينهارت

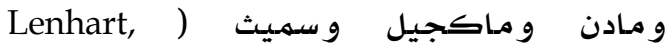
أن (Madden, Macgill, \& Smith, 2007

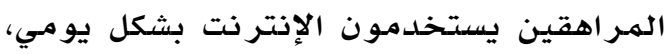

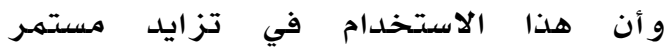

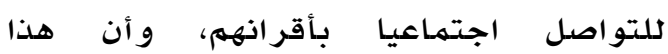

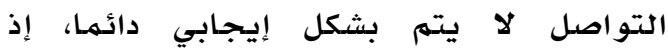

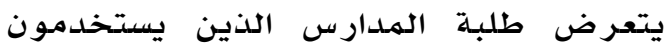

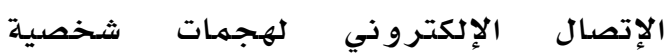
و تحرش بشكل يومي، ويتم نقل الانفعالات

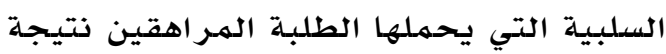

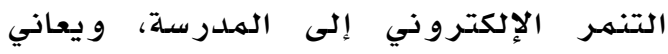

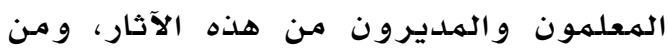

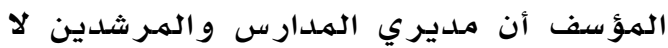

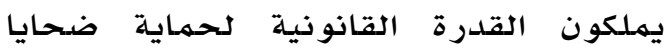
الإنتر نت، وحتى الطالب الضحية لانو يستطيع

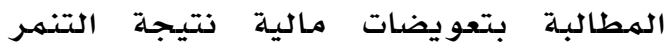

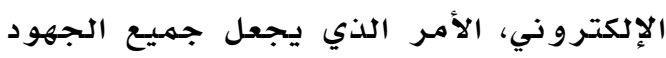

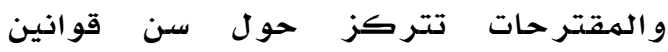

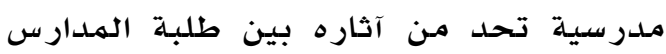
.(Anderson, 2007)

وبتطور وسائل الاتصالات الإلكترونية

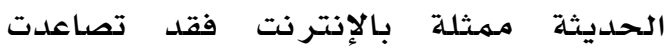

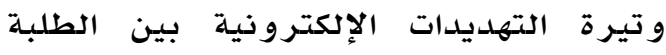

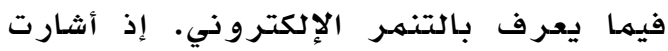

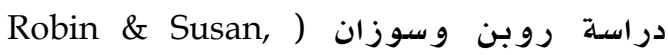


حيـاة الطاسب ) Litz, 2005; Bery \& Hunt,

كما أثبتت بعض الدراسات أن آثـار التنهـر

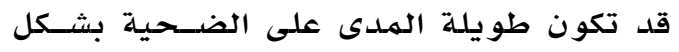

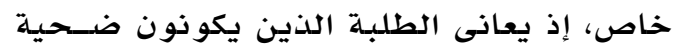

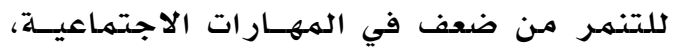

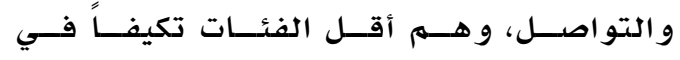

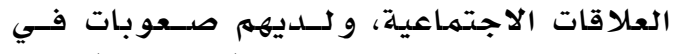

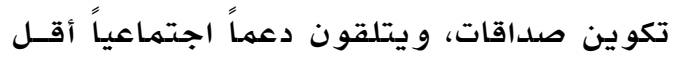
مـن غيـرهم الــذين لا يتعر ضــون للتنهــر (Eslea, Menesini, Morita, O'Moore, ،Moramerchan, Pereira, \& Smith, 2004) كما إن الطلبة الذين يقعون ضحية لسـلوك

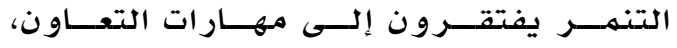

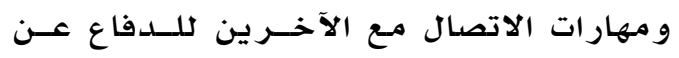
أنفسـهـ (Delfabbro, Winefield, Trainor, ) Dollard, Anderson, Metzerm, \& .(Hammarstrom, 2006 من جهة أخرى، قد يكتسب الطلبة سـلوكات

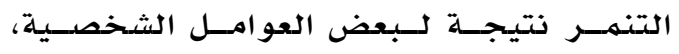

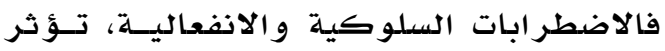

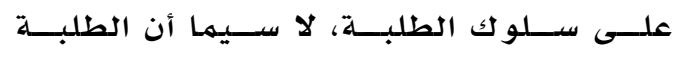

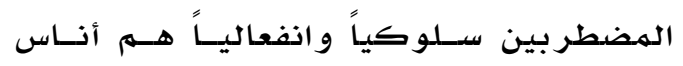
أسوياء في الأساس من حيث قدر اتهم العقلية والجسمية، و لكن الفرق بينهم وبين الأطفال

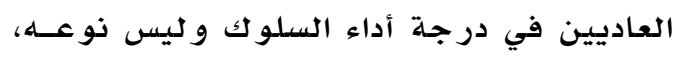

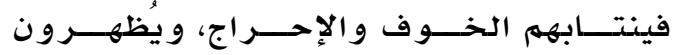

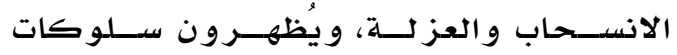
عدوانية، و عدم ثقة بـالآخر ين (أنجشـايري، .) (r.10

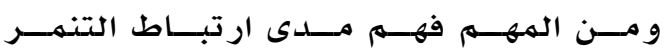

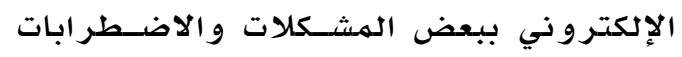

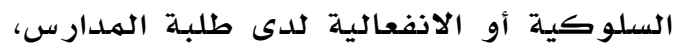

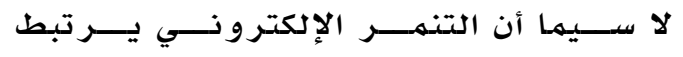

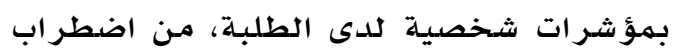

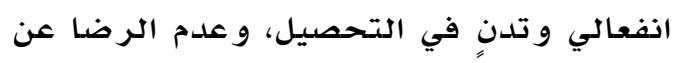

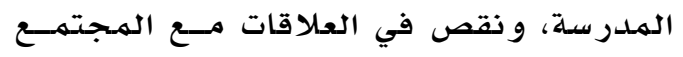

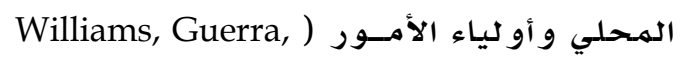

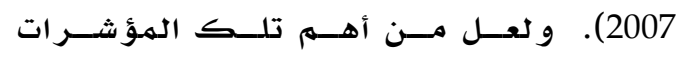

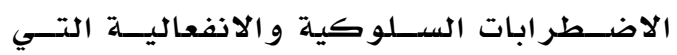

المدرسة مساعدة وحماية الطلبة، وحماية المدرسة نفسها من العوائق القانونية، ودعال

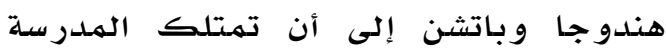

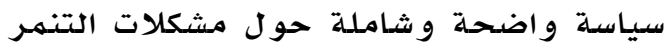

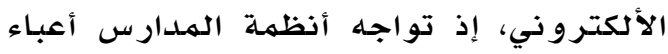

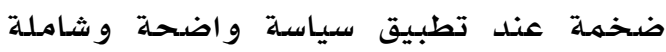

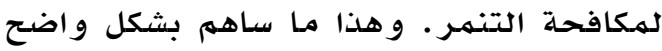

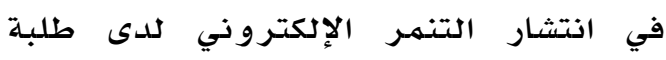
المدارس.

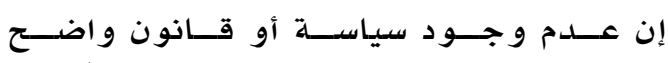

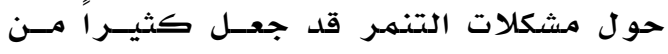

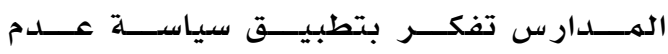

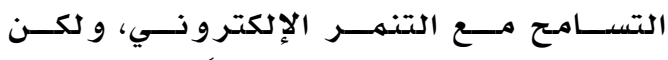

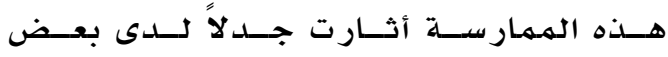

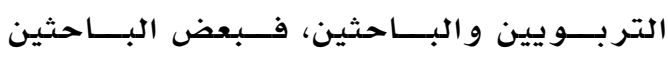

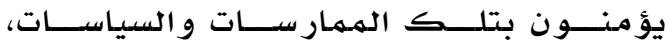

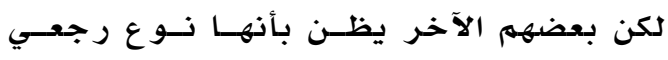

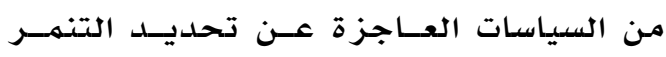

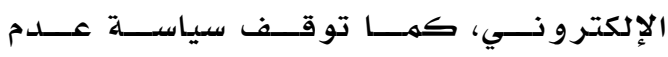

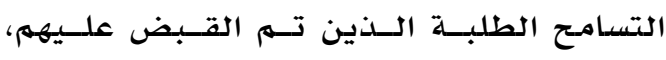

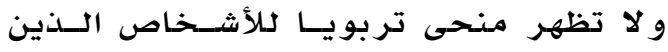

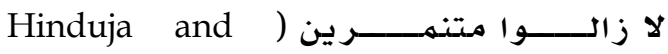
.(Patchin, 2008 وتسعى المدارس جاهـدة للحســ مـن التنهـر

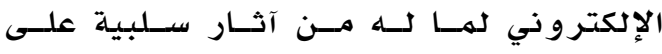

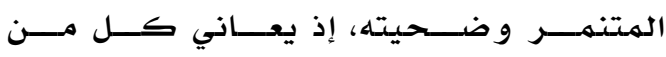

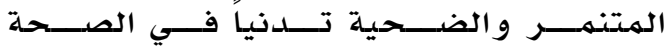

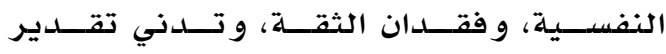

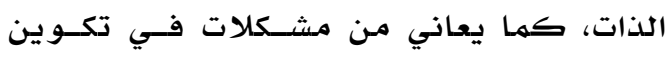

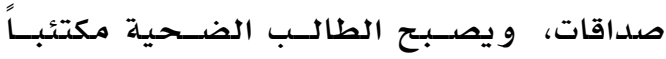

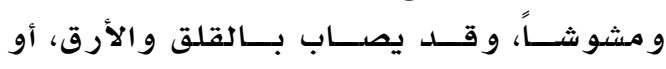
يصبح عنيفاً و منسـحباً، وقــــ يـؤدي التتنهـر

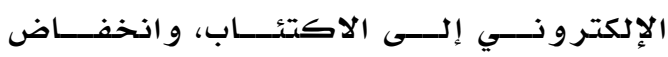

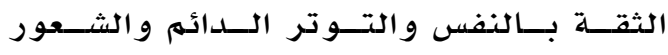

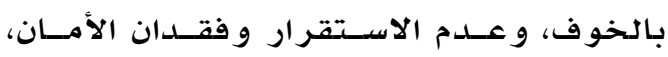

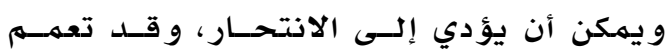

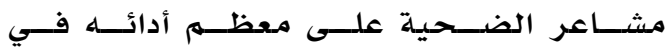

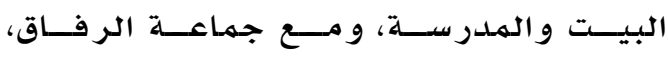

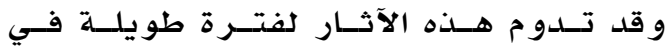


يمكن أن تصنف تلك الاضطرابات على أنها

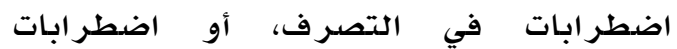

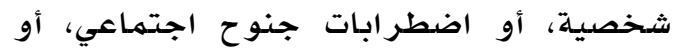

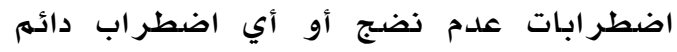

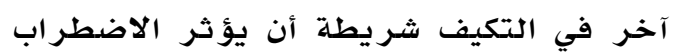

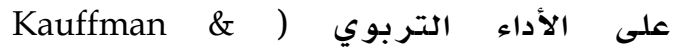

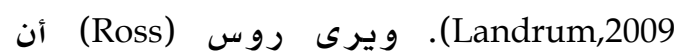

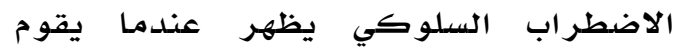
الطفل بسلو ك ينحرف فن المعيار الاجتماعي بحيث أنه يحدث بتكرار وشدة، بحيث يحكم عليه من أشخاص بالغين و أسدوياء بأنه عمل

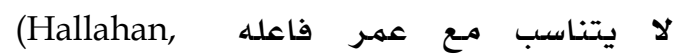
.Kauffman \& Pullen, 2009)

إن تعدد التعريفات التي قلدمت لوصف

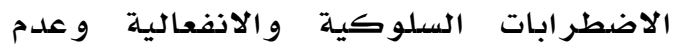
اتفاق الاختصاصيين في التوصل إلى تعريف

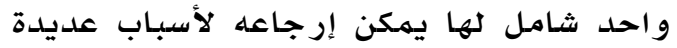
تمثلت بحسب ما أشار إليها \&auffman \&

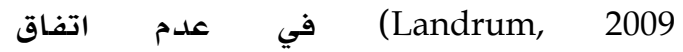
الاختصاصيين على معنى السلوك الطبيعي

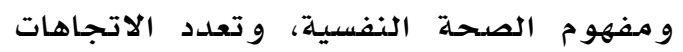
و اختلاف النظريات التي تفسر اضطر ابات

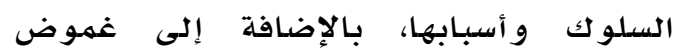

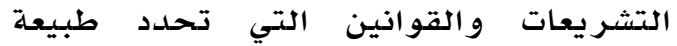
الاضطراب السلوكي، والتباين في معايير

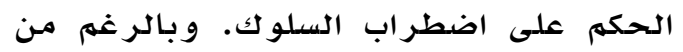

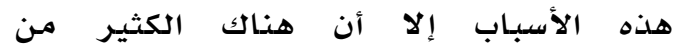

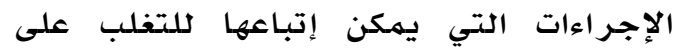
مشكلة تحديد السلو كل المضطرب من عدمبه تستند غالبيتها إلى محكات تمييز السلولوك

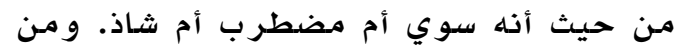

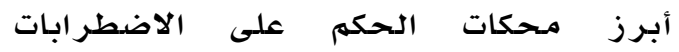

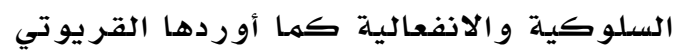

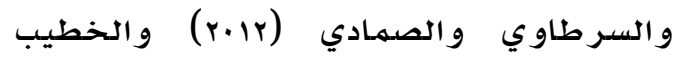

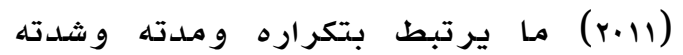

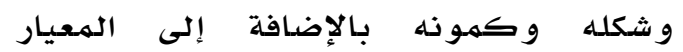

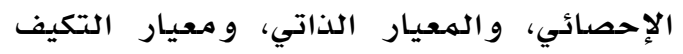

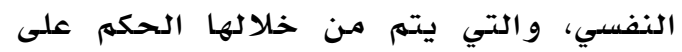
السلوك. ويتهم تشخيص الطلبة الذين يعانون

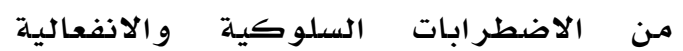

أصبحت من أكثر المشكلات الأسساسية شيوعاً

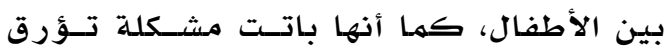

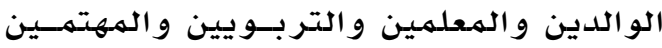

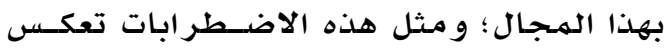

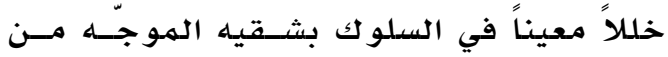

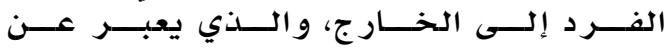

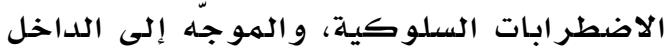
و الذي يعبّر عن الاضطر ابات الانفعالية.

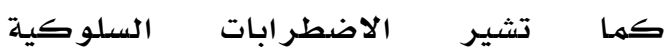
والانفعالية إلى مجموعة مـن الأفراد الذين الذين

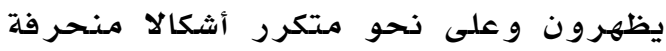

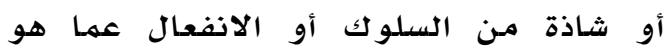
طبيعي أو متوقع، حيث استخدم المتخصصصون

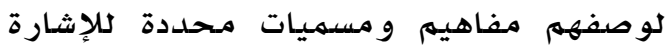

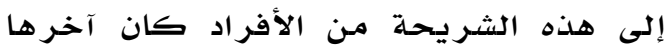
و بحسب الاتجاهات الحديثة في مسجال التأهيل

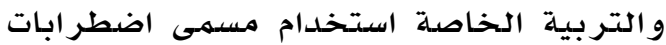
السلوك؛ و ذلك لأن هذا المسسى أعم و أشهمل من غيره من المصطلحات و والمسيميات الأخرى. كما أنه يشمل قطاعا واسعا من فيره

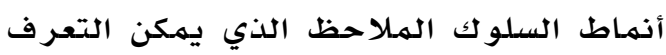

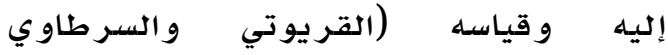

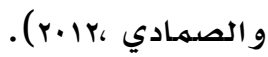

ويعرف التجمـع الوطني للصحة العقلية و التربية الخاصة Health and Special Education Coalition الاضطراب السلوكي على أنه إعاقة تتصف

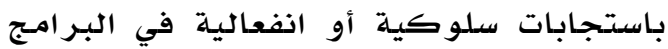

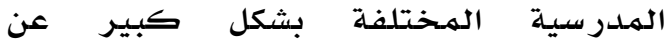
المعايير العمرية، أو الثقافية، أو العرقية الهية

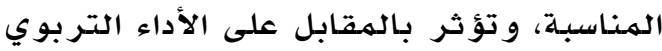

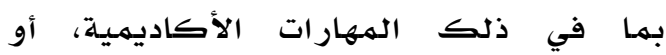
الاجتماعية، أو الشخصية. وقد ت تكون هذه

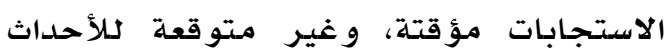
البيئية الضاغطة، وتظهر بشكل مستهمر في

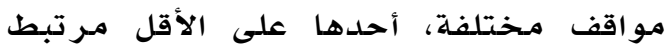

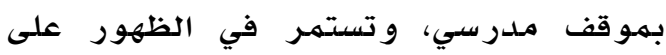

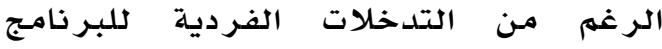

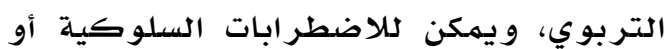
الانفعالية أن تحدث مـع إعاقات أخرى. كها 
بـــين الطلبـــة الهتتنهــرين و الطلبـــة غيــر

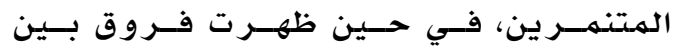

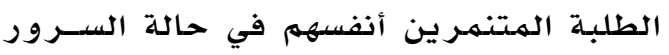

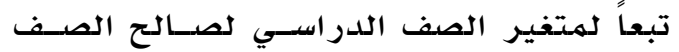
الدراسي الأدنى، و في حالات الخوف و الغضب

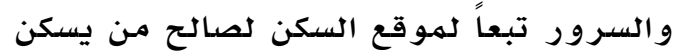
منهم في المدينة، كما أظهر ت النتائج وجود دان ارتبــاط سـلبي دال بــين الحالــة الانفعاليسـة

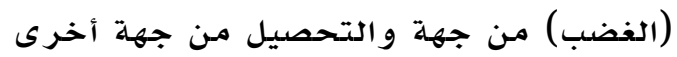
لدى الطلبـة المتتنمرين.

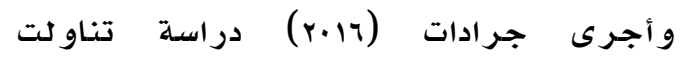

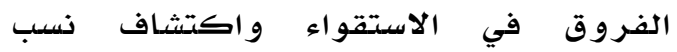
الاستقواء والوقوع ضحية بينهم. شملت عينة

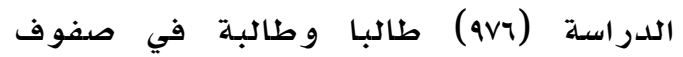

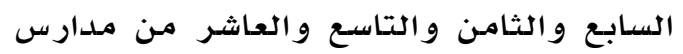

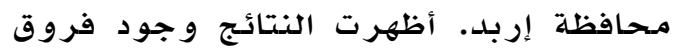

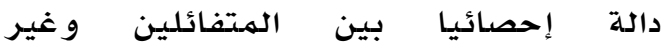

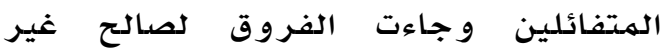
المتفائلين، كما أن نسب الاستقواء و الوقوع أوعاء ضحية كانت أعلى مها هي للدى المتفائلين. و في دراسـة قام بها الزهر اني (الامت

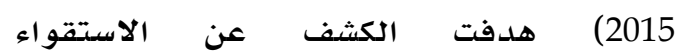

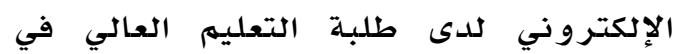

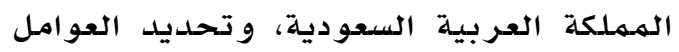
المحتملة المؤثرة في الاستقواء الإلكتر وني. تكونت عينة الدر اسـة من (r^v) طالبـا وطالبهة،

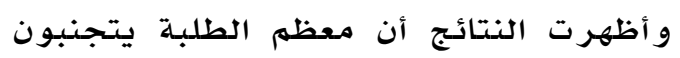

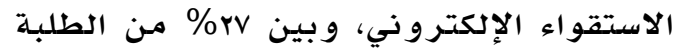

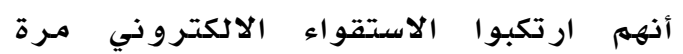

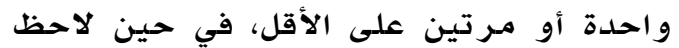

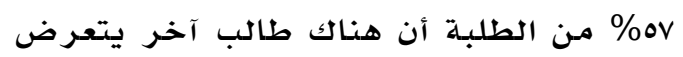

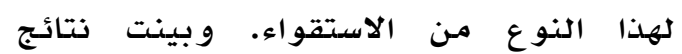

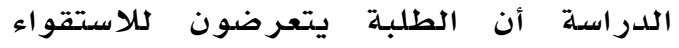

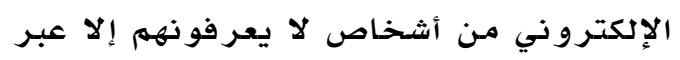
الانترنت، ويرون في الاستقواء الإلكتروني ظاهرة خطيرة، تمارس من الذكور أكثر

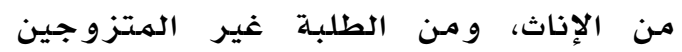

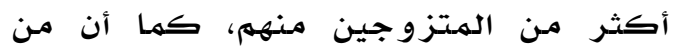
يستخدم جهازه الخاص يتعرض لهر للاستقواء
باستخدام الملاحظة المباشرة للسلوك ك أو

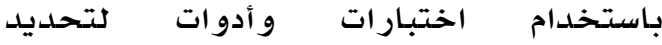
الاضطر اب الانفعالي السلوكي و مستواه، وقدا تأتي هذه المـلاحظات من تقديرات المعلمينين وتقديرات الوالدين وتقدير ات الاختصداصيين

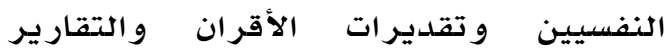

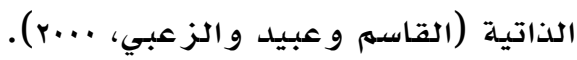
حظيت الاضـطر ابات السـلوكية و الانفعاليـة باهتهـام كبيـر خاصــة علـى صــيد إجــراء

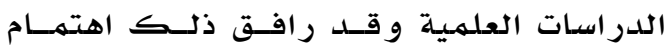

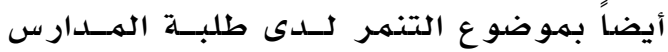

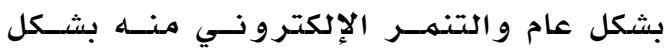

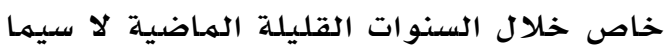
في الدراسات الأجنبيـة منهـا. إلـا أن ذلــك

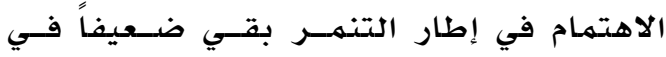

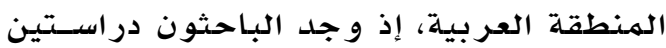

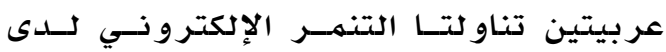
الطلبـة، إحداهمـا في مصر قــام بهـا العثمــان

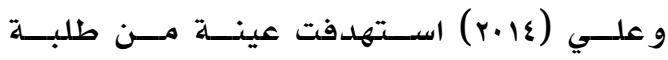
التعليم العام، و الأخرى في السعودية قام بهـئ الز هر اني (Al-Zahrani, 2015) استهديمت عينة

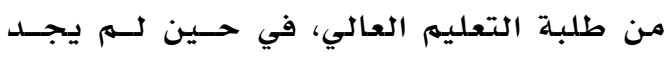

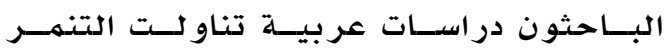
الاككتروني لدى الطلبـة المضطر بين سلوكياً

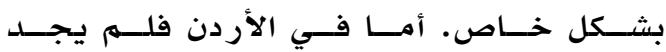

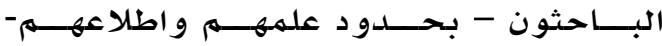

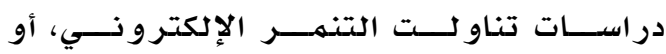

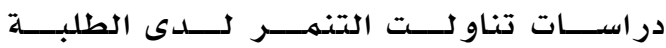
الهضطر بين سلوكياً. فقد قـام بنــي يــونس (r.17) بدر اسلة للكشف عن الحالات الانفعالية للطلبــة الهتتنهــرين مقار نــة بالطلبــة غيـر

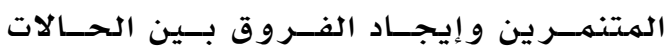

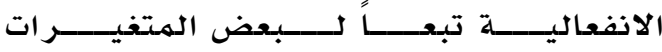
الديمو غرافية لدى الطلبة المتنمررين. تكوّنت

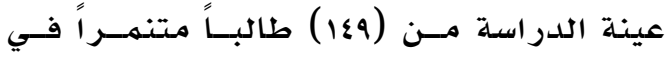
الصفوف السـابع و الثـامن و التاســع و العاشــر الأساسي و الأول الثاذوي الههني و (يء1ا ) طالباً

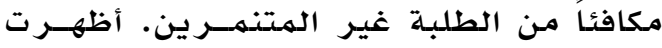

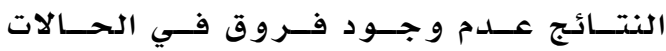
الانفعالية (الخوف، الغضب، الحزن، السرور) 
أثارا على الجـانب الانفعالي للدى طلبـة المدارس أكثر من التنهـر التقليدي. و بهدف التعرف إلى ماهية التنهـر الإلكتروني

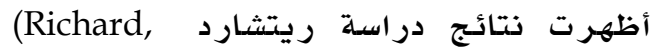

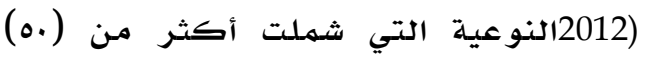

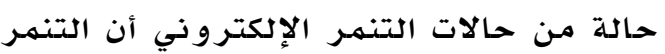

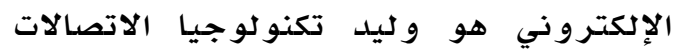
الحديثة التي وسعت نطاق مشكلات التتنمر

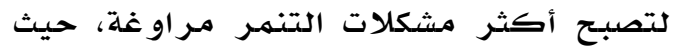

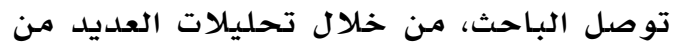
القضايا لفهم قضية التنهمر الإلكتروني، إلى إلى

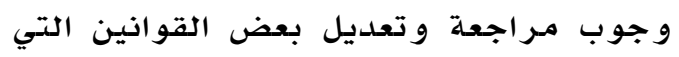
تقف عقبة لاتخاذ بعض إجر اءات تخفيف آثار

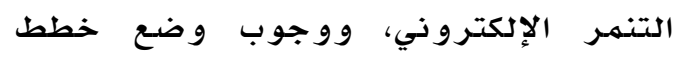

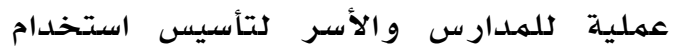
آمن لوسائل الاتصالات.

و فــي إطـار التعــرف إلـى طبيعــة التتهـــر

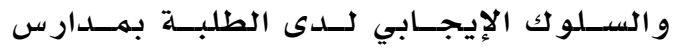
التعليم العام و مدارس التربية الخاصدة أجرت

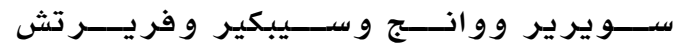
Swearer, Wang, Maag, Siebecker \& در اســة علـى عينــة بلغــــ (Frerichs, 2012)

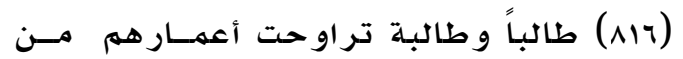

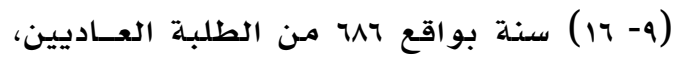

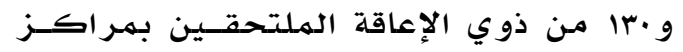

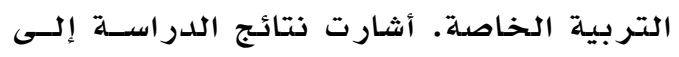

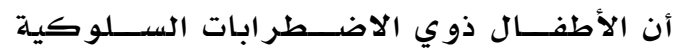

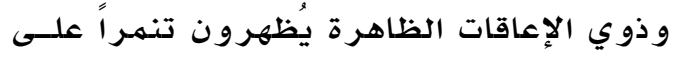

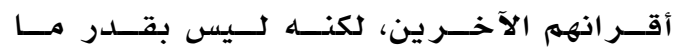
يتعرضون إليه من تنهمر في مدارس التعلـيهم

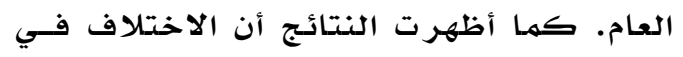

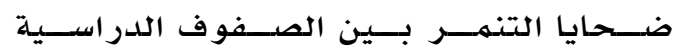

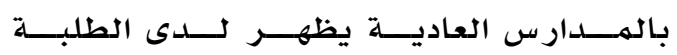

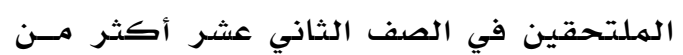

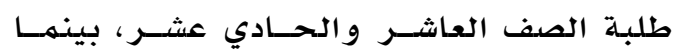
ليس هنـاك فـرق فـي التتنهـر فـي صــفوف مر اكز التربية الخـاصـة، و لهم تُظهر النتــائج

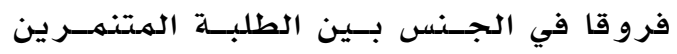

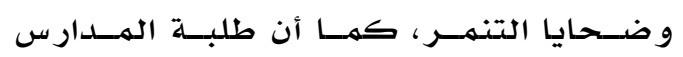

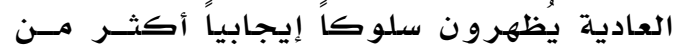

الإلكتروني أكثر من الشخص الذي يستخدم

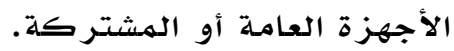

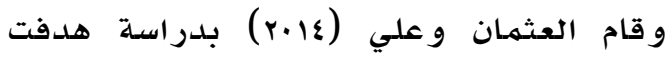

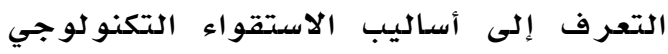

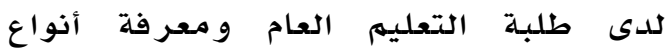

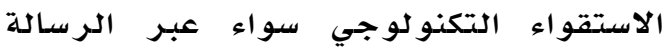

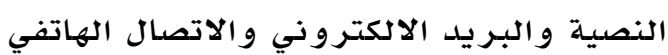

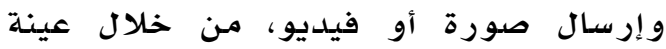

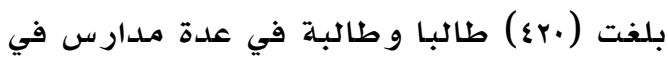
محافظتي القاهرة و والقلوبية، تر اوحت

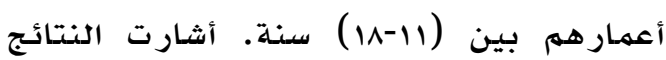
إلى اختلاف الاستقواء التكنو لوجي بين طلبـة إسبة

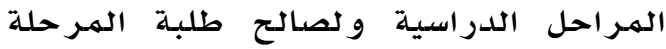

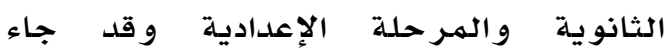
الاختلاف في بعد الاتصال الهاتفي.

و أجرت خوج (r.1r) دراسلة هدفت التعرف إلى الفروق بين مستويات التتنمر و علاقتها

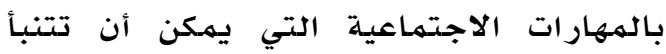

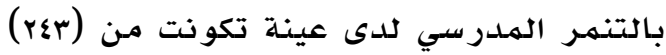

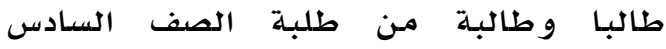

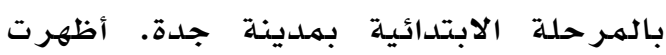
النتائج وجود فروق بين متوسطي درجات مرتفعي التنهـر و منتخفضي التتهمر لصالح

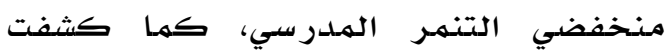
النتائج عن علاقة دالة وسالبة بين التنهمر المدررسي و المهار ات الاجتمـاعية.

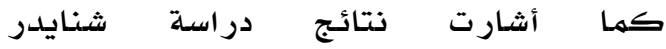
وزمـائه (Schneider et al., 2012)، الهادفة إلى دمانى الكشف عن العلاقة بين التنـمر الإلكتروني

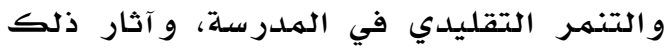

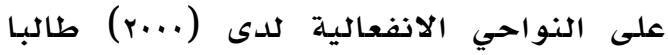
وطالبـة في مدارس مترو الغربية في مدية ادينة

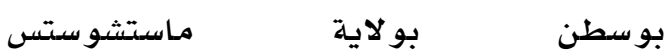
(Massachusetts)

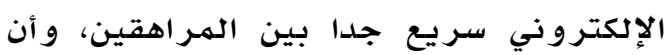
هنالك علاقة طردية بين التتنمر الإلكتروني

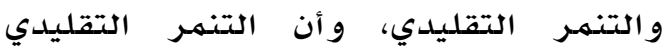

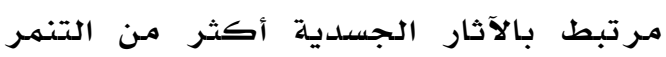
الإنكتروني، في حين أن للتنمـر الإلكتروني 
على فهم أفضل لتأثير التنهمر الالكتروني

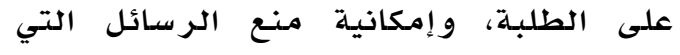

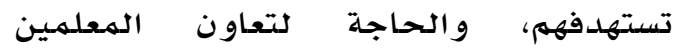

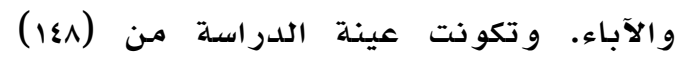

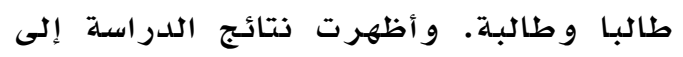

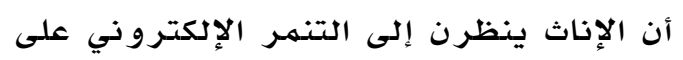

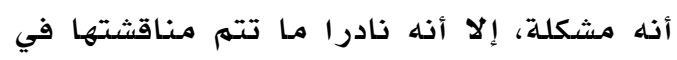

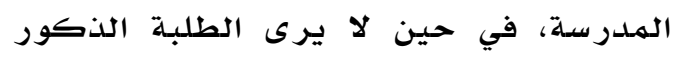

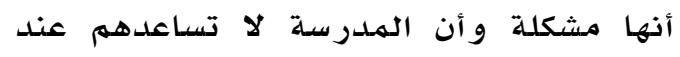
التعامل مـع التتهمر الإلكترو ني. كمان التها أشسارت

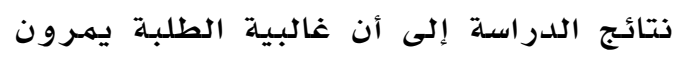

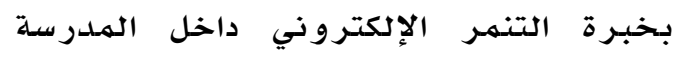

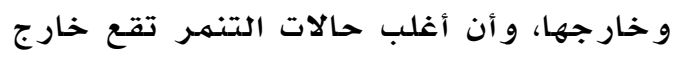

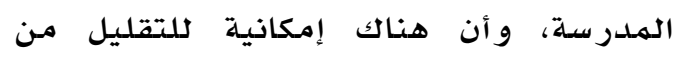

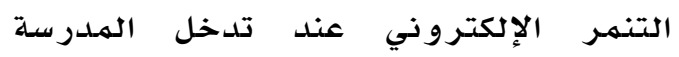

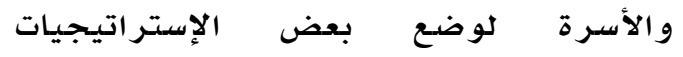

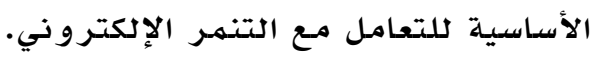
و لمعر فة نسب انتشار التنمر الإلكتر وني لدى

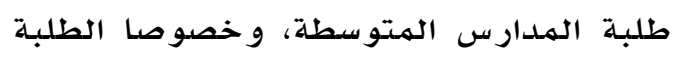

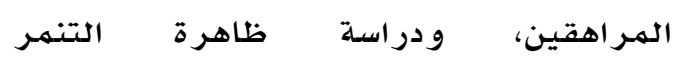

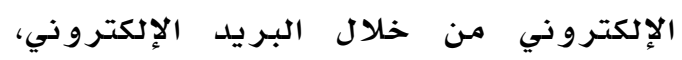

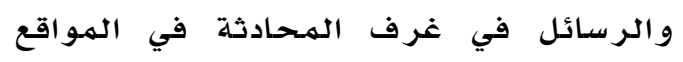
الإلكترونية، أو عبر الر سائل الرقمية أو الو الهرية

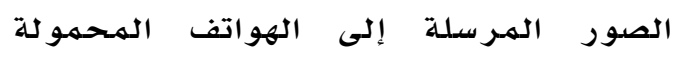
قام (Robin \& Susan, 2007) بدر اسـة تكونت الفولت عينتها من (rVTV) طالبا وطالبية في صفوف

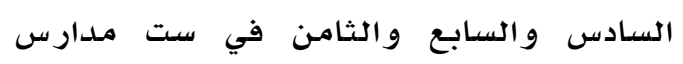
متوسطة في الجنوب الشرقي و والشمال

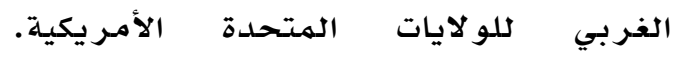
و أظهرت النتائج أن (11\%) من الطلبة قد التد

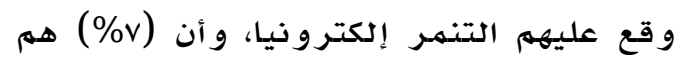

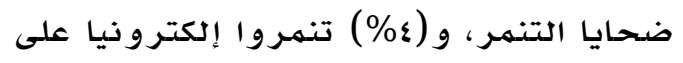

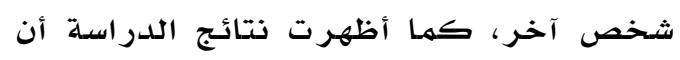

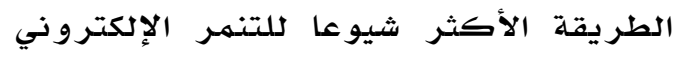

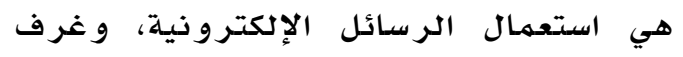

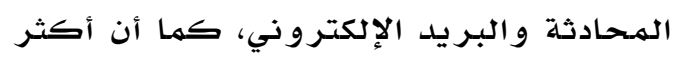

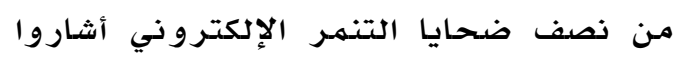
بأنهم لهم يعرفوا هوية الهتتنهر .
طلبة الهـراكز الخاصـة من ذوي الاضطر ابات السلوكية وذوي الإعاقات الظاهرة.

Kowalskia \& Fedina, أما كو السكا و فيــنـا (2011) فقد قام بدراسة هــدفت إلـى فحســ

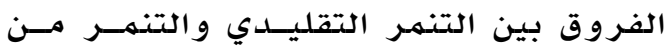

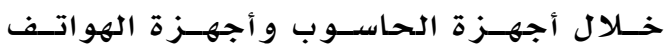

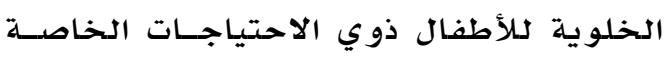
وذوي النشاط الزائد وومدى ارتباطه بالصحسة

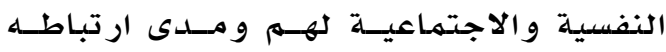
بفهم الوالدين لطبيعسة التتهــر الالكترونــي.

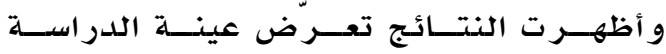

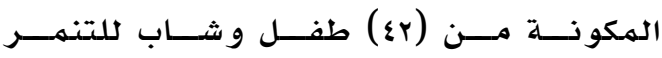

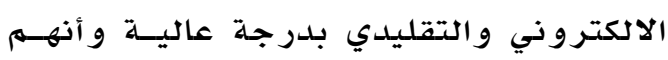
أكثر حاجهة للتواصل مـع آبـائهم، حيـث تـهم التوصل إلى النتائج في ضوء نظريــــ العقـل لهم و للآخر ين.

Buffy \& Dianne, كما توصل بفي وديان

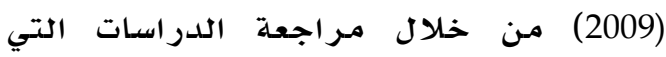

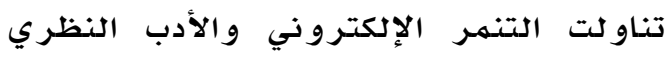

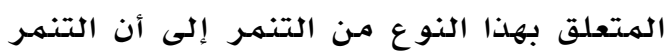

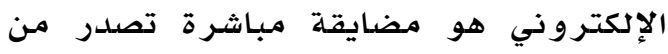

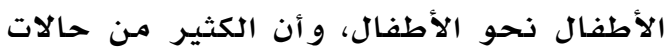
التنـمر تحدث في البيت، وتنتقل نتائج هذهاه

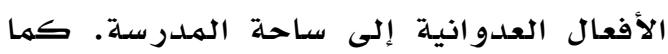

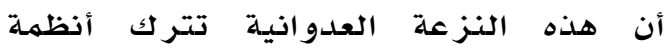
المددرسة في حيرة وعدم قدرة على توقع

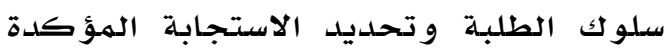
لهثل تلك السلوكات، أو تحديد متطلبـات

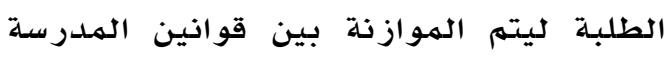
و تلك السلوكات. و أن الكثير من مشكلات

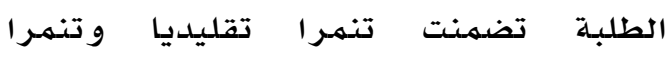
إلكترونيا، وتم توظيف مواقع التواصل

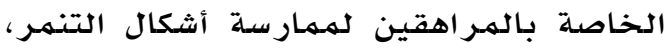

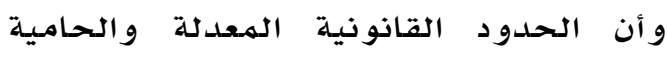
لحقوق الطلبة لا تزال غير كافية لهنع

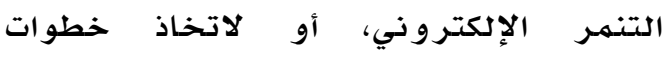
استباقيـة.

Patricia, أمـا دراسـة باتر يشيا وروبن ووسدوزان فقد هدفت الحصول ولونو (Robin \& Susan,2007) 
مضدايقة الضحية عـن بعـد و بشـكل مسـتهـر ، حيث يُعد التنهمر الإلكترووني مشكلة عصدرية ذات آثار سلبيـة كبيرة، سـواء علـى مســتوى

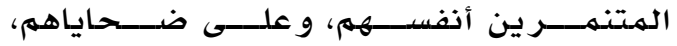
فالهتنهـر و الضحية خلال ل التنهـر الإلكترو نـي يعيشــون فتـرات مـن الاضـطر اب الانفعـالي أطول من أشكال التنهـر الأخرى، مهــا يجعـل كل مـن المهتنهـر و ضدحيته يعانيان تدنياً فـي الصدحة النفسية، وتقـلـير الــذات، و مشـكلات ســلوكية و انفعاديــة، و ضذغوطات مـرتبطـة بالتكيف النفسي العام، حيـث يصـبـح ضـحية

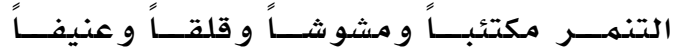

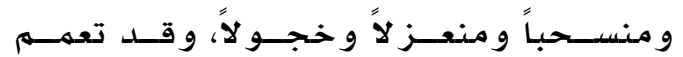
مشاعر الضحيـة على معظم أدائه فـي البيــت

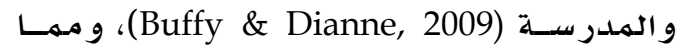
يزيـ الأمـر سوء" لدى طلبـة المسـارس تفـاعـل عوامــل متعــددة مـــع التتـهـــر الإلكترو نــي، كالاضطراب الانفعالي السلوكي الذي يزيد من حدة التنهمر الإلكترووني، و يضاعف آثـاره على الطلبــة (أنجشـايري، 10 مبr). مسن هنـا تظهر مسوغات البـحث فـي موضـوع التتنهـر الإلكترو ذي لها لهذا الهووضوع الحسـيث مــن أهميـة كبيرة على الطلبـة وخصوصاً الطلبـة المضطربين سلو كياً خاصــة فـي ظـل عـدم و جود سياسـة أو قانون واضسح حول مشـكلات التنهـر و تأثيرها ها على هـؤَلاء الطلبــة، الأمــر الذي يتطلب بـالضرورة قياس مستتوى التنهمر لتحدلديد العوامل التـي تـؤدي إلـى انتشـاره، و سبل تخفيـف آثـاره السـلبيـلة. لـذا، يتضـح هدف الدرراسـة الرئيس فـي معرفــة مســتوى التتهـر الإلكترووخي لدى الطلبـة المضـطربين سلوكياً و انفعالياً في مدينة الزررقاء و علاقة ذلــك بــبعض المتغخيــر ات، و بشــكل أكثـر تححليدا تتلخص مشكلة الدراسـة الحـاليـة فـي محاو لتها الإجابة عن السؤالين الآتيين:

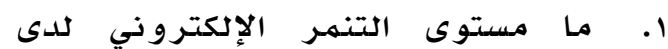
الطلبـة المضطربين سلو كيا وانفعاليا في مدينة الزروقاء؟

Y. هل توجد فروق ذات دلالة إحصدئية

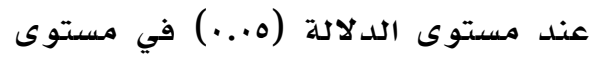

ومن خلال الاطلاع على الدراسات السابقة

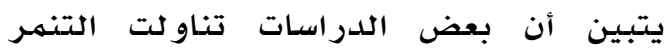

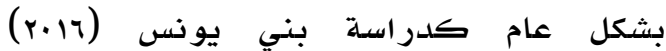

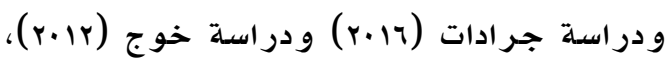
وبعضها الآخر قد تناولت التنمر الإلكتروني

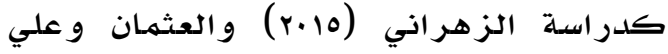

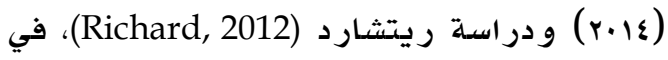
حين تناولت بعض الدراسات التنمر التقليدي

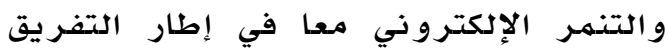
بينهما، ومن تلك الدراسات دراسة شنايدر وزملائه \& Schneider, O'Donnell, Stueve ودراسة كوالسكا و فيدنا (Coulter, 2012) (Kowalskia \& Fedina, 2011) تحديد موقع الدراسة الحالية من الدراسات

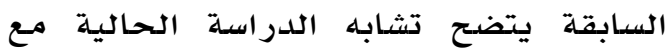
بعض الدراسات الأخرى التي تناولت التنمر

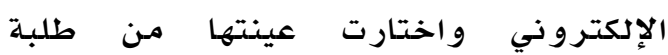

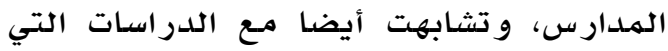

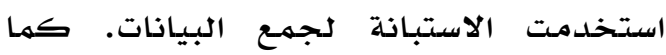

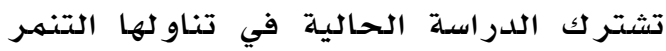

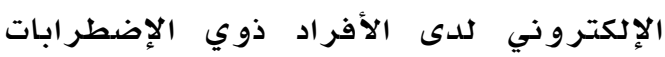

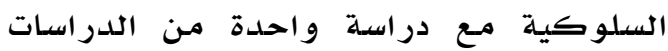
السابقة هي دراسة سويرير ووانج وسيبكير

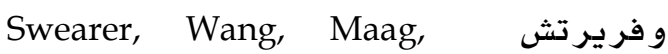
(Siebecker \& Frerichs, 2012) الدراسة تتميز عن بقية الدراسات السابقة

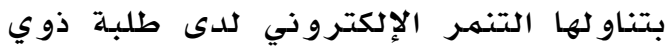

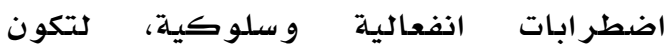
الدراسة الحالية الدراسة الأو لى - في حدود التهالية

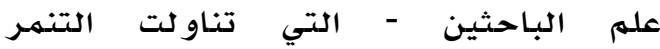
الإلكتروني لدى الطلبة المضطربين انفعاليا و سلوكيا في الأردن بشكل محدد. مشكلة الدراسة و أهدافها و أسئلتها أشـارت العديد من الدراسـات المحليسة التسي

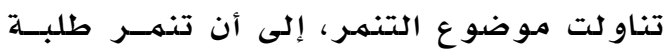

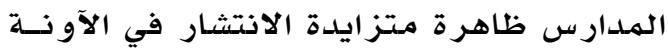

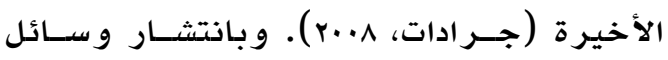

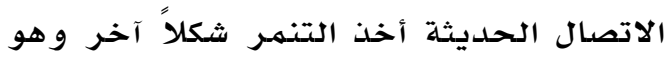

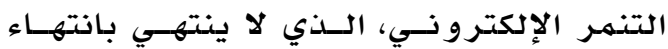

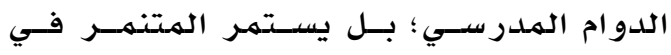


الشاملة للبنات، وتتبع هذه الهـدارس لمديرية تربيـة وتعليهم الزرقاء الأو لى.

-الحدود الزمانية: أجريت هذه الدراسـة في

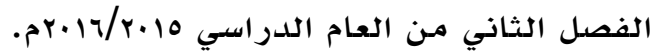

أما محددات الدر اسلة فقد تمثلت بما يأتي: صدق و وثبات أدوات الدراسة التي استخدمت لجمـع البيانات.

عينة البـحث المتمثلة بطلبة من

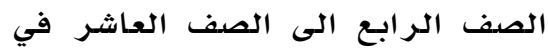
مدارس تتبع مديرية تربية وتعليم منطقة الزرقاء الأولى.

مصطلحات الدراسة التنمر الإلكتروني: يعرف التنهمر الإلكتروني

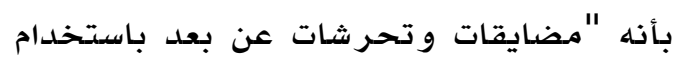

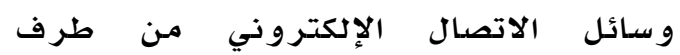

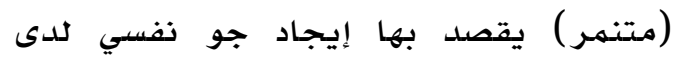

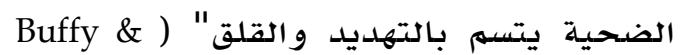

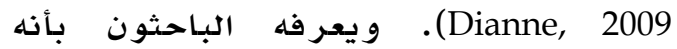
التحرشات التي يقوم بها طلبة مدرسة حي

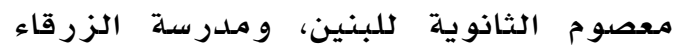

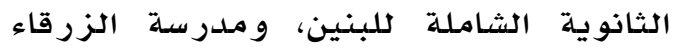

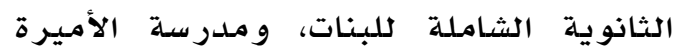
رحمة الثانوية الشاملة للبنات باستخدام

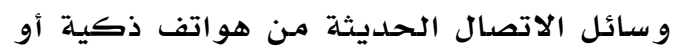
بريد إلكتروني أو و وسائل الإتصالات

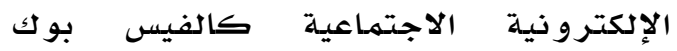

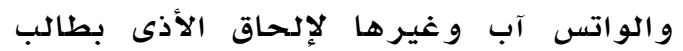

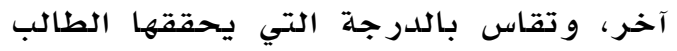

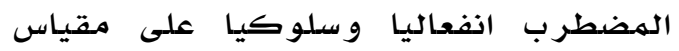
التنـمر الإنكترو ني المعدد في هذه الدراسلة. الطلبة المضطربون سلوكيا وانفعاليا: يعرف الطلبـة الهضطربين سلوكيا وانفعاليا

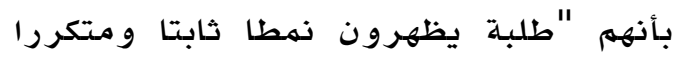

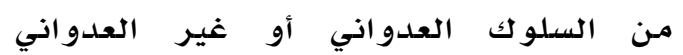

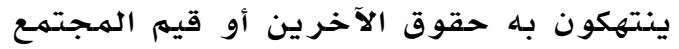

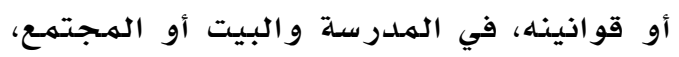
على أن يكون هذا السلوك أكثر من مجري آكرد

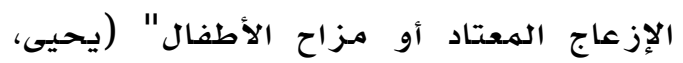

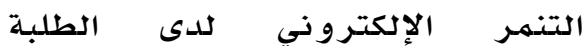

المضطربين سلوكيا و انفعاليا تعزى المى

لمتغير ي الجنس و العمر ؟

أهمية الدراسة

تنبع أهميلة هذه الدراسة من أهمية الموضوع

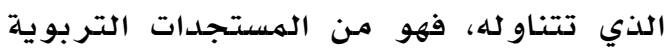
التي نتجت عن تطور وسائل الاتصدالات، ويمكن إيضاح أهمية الدراسة في فئور بعديها النظري والتطبيقي على النحو الآتي:

الأهمية النظرية: توفر هذه الدراسة إطارا نظريا عن التتهمر الإلكترووني يمكن الاستفادة

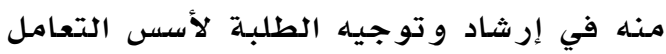
مـع تكنو لوجيا الاتصالات الحديثة، كما توفر حقائق و معلومات حول ارتباط التنهـر الإلكتروني بعض الاضطرابات الانفعالية و السلو كية.

الأهمية التطبيقية: توفر هذه الدراسـة مقياسا للتنـمر الإلكتروني يمكن توظيفه في

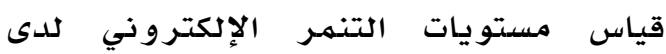

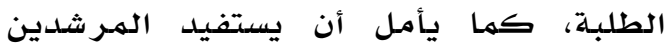
والهدرسين من نتائج الدراسة في توجيه

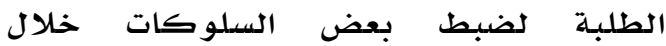
تواصلهم باستخدام الهواتف الذكية، ووسائل الاتصال الإلكترووني. كواهما قد تفيد نتائج هذه

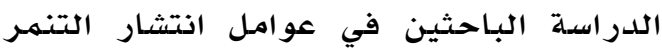
الإلكترو ني و أسبابه، وكيفية تخفيف آثاره. حدود الدراسة ومحدداتها حددت هذه الدراسة بعدد مـ الحدود و التي تتمثل بها يأتي: الحدود البشرية: تكونت عينة الدراسـة من ال البا و وطالبة.

الحدود المكانية: اقتصرت هذه الدراسـة على

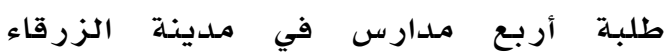
بالأردن، ووهي: مدررسة حي معصدوم الثانوية للبنين، و مدررسة الزروقاء الثانوية الثاملة الثلة

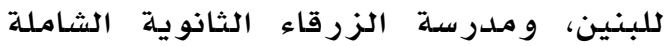

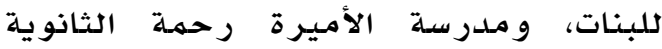


المسح الشامل، وقد توزعت عينة الدرراسة حسب متغيري الجنس والعمر كما في جلدول

جدول

توزيع الطلبة ذوي الاضطرابات الانفعالية والسلوكية وفقا

\begin{tabular}{|c|c|c|c|}
\hline النسبة & العدد & مستوى المتغير & المتغير \\
\hline$\% Y Y, \varepsilon$ & r & من · ا سنوات إلى ب ا سنة & \\
\hline$\%$ \% , 0 & ए & أكبر منة با سنة و أقل من & العمر \\
\hline$\% \leq 7,1$ & $0 \leqslant$ & من ع ا سنة فأكبر & \\
\hline$\% 1 \ldots$ & $11 \mathrm{~V}$ & المجموع & \\
\hline$\% 09$ & 79 & الذكور & \\
\hline$\%$ \&1 & $\leqslant \wedge$ & الإناث & 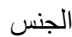 \\
\hline$\% 1 \ldots$ & $11 \mathrm{~V}$ & المجموع & \\
\hline
\end{tabular}

يتبين من جدول ا أن أكبر عدد مــن أفـر اد

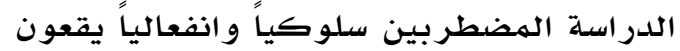

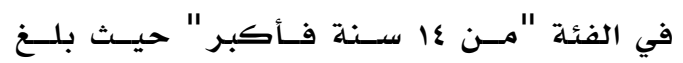

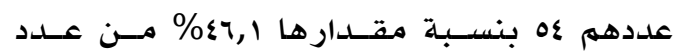

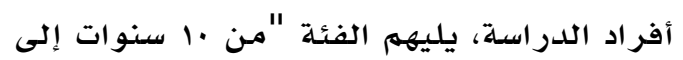

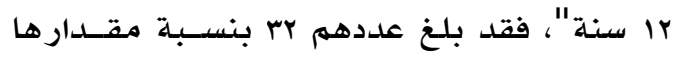

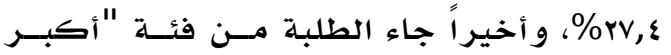

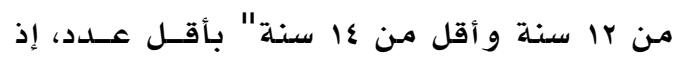

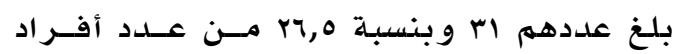
العينـة. كما يتبين أن وجا مـن أفر اد الدراسـة

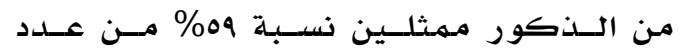

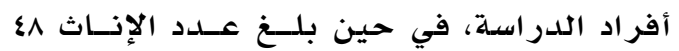
بنسبة اء\% من عدد أفر اد الدر اسـة.

أداتا الدراسة

تمثلت أداتا الدراسة بمقياس ووولكر لقياس

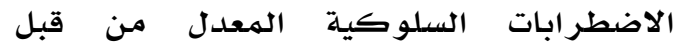

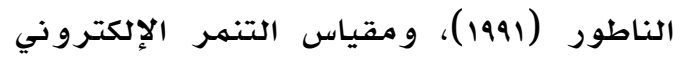

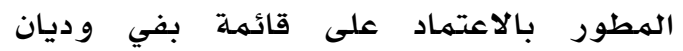

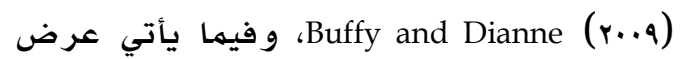

$$
\text { تفصيلي لأداتي الدراسـة. }
$$

أولاً: مقياس وولكر كلاضطر ابات السلوكية Walker Behavior Problem Identification هـو مقيـاس يهـــف التعـرف ف إلـى Checklist

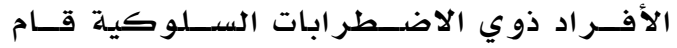

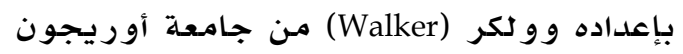

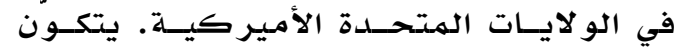

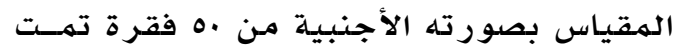

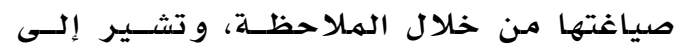
أشكال من السـلوك غير التكيفي الســي يمكـن فئن

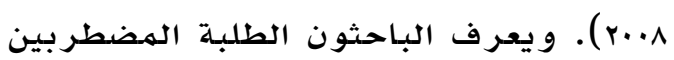

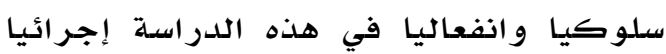
بأنهم الطلبة الذين يظهرون سلوكات غيلواتير

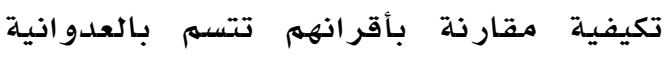

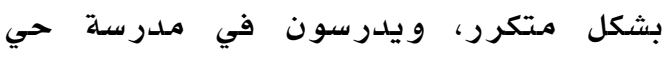

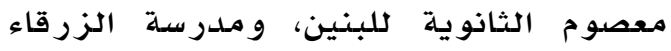

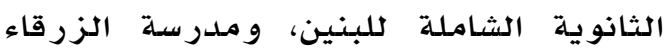

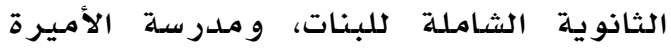

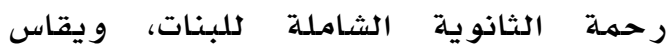

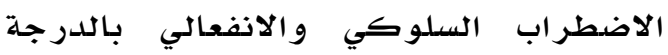

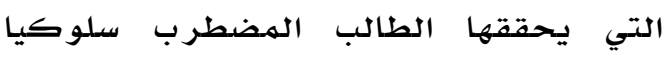

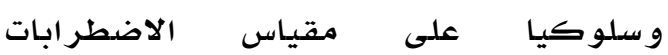
السـلوكية للناطور (1991). الطريقة والإجر اءات

منهج الدراسة

الدر اسـة الحالية هي دراسلة و صفية استخدمت

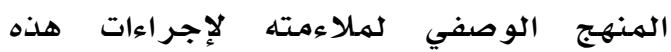
الدراسة الهادفة التعرف إلى مستوى الهو التنهر الاككتروني لدى عينة من الطلبـة الهضطر بين الهـين

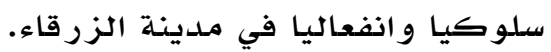
مجتمع الدراسة وعينتها تكون مجتمـع الدراسة من جميع الطلبة الذين يعانون من اضطرابات سلوكية وانفعالية في ماتي مدارس الذكور والإناث في مدينة الزروقاء

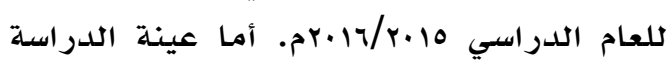

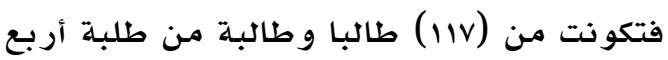
مدارس، هي: مددرسة حي معصوم الثانوية

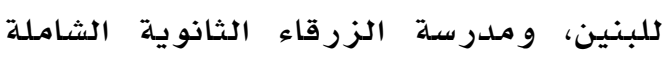

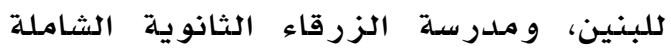

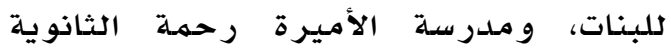

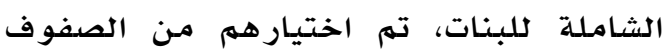

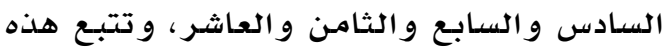

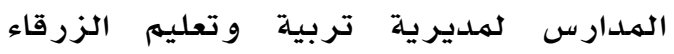
الأولى، وجرى اختيار عينـة الدراسـة بالطريقة

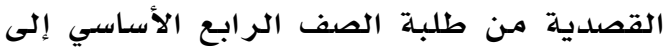
الصف العاشر الأسـاسي خلال الفصل الثاني

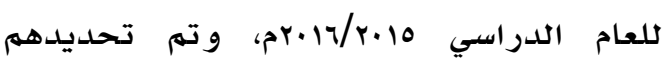

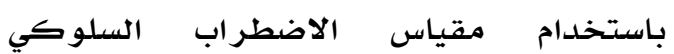

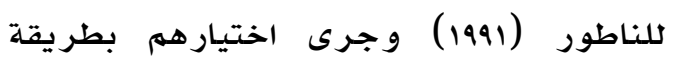


مـع كل بعد تنتهمي إليه، وومـع الدرجة الكلية

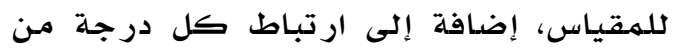

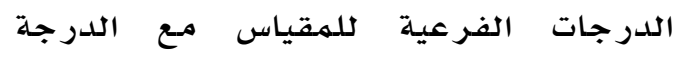

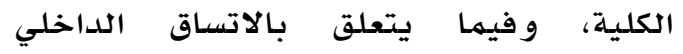

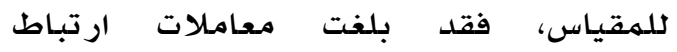

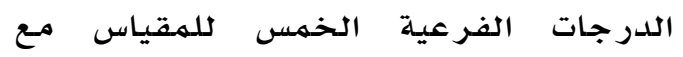

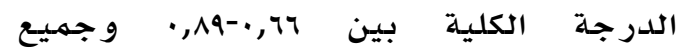
معاملات الارتباط كانت ذات دلالدة إحصائية

أما ثبات المقياس بصورته الأردنية، فقد تم استخراج دلالات ثباته مـ خلال اختيار عينة

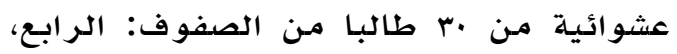

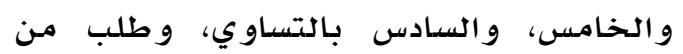
معلمين اثنين يمتتلكان معرفة جيدة بالطلبة الذين تم اختيارهم عشوائيا، تطبيق مقياس

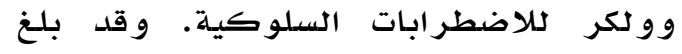

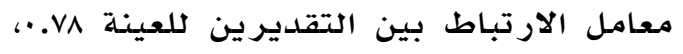

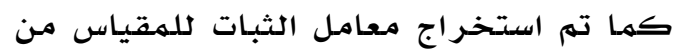

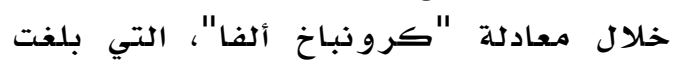
درجتها به, • (النـاطور، 1991).

توصل الباحثون إلى دلالات الثبات للمقياس

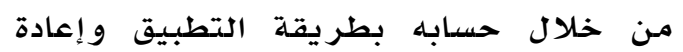
التطبيق، وجرى تطبيق المقياس على عينة

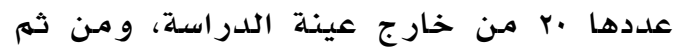

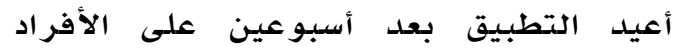

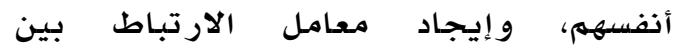

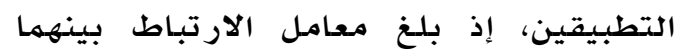

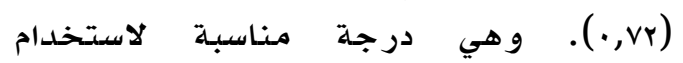
الهقياس للتعرف إلى الاضطرابات السلوكية لدى طلبة المدارس. ثانياً: مقياس التنمر الالكتروني قام الباحثون ببناء مقياس التنمـر الإلكترونسي من خلال إجـراء ما يلي:

ا. Buffy \& ترجمسة قائمسة بفـي وديـان

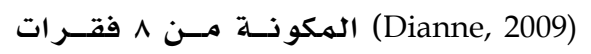

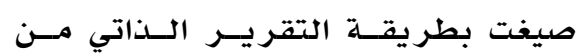

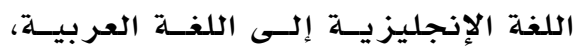

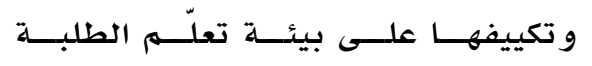

أن يظهره الطلبـة فـي الهــدارس. وتوزّعـت فقرات الهقياس علـى خمســة أبعـاد فرعيسة

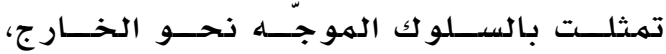

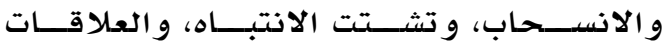
المضطر بـة مـع الأقران، و عدم النضـج.

صدق المقياس وثباته في صورته الأجنبية:

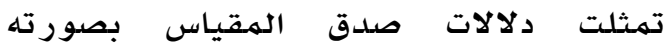

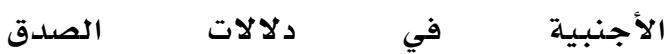
التمييزي Contrasted Group Validity و ودلالات الصدق العاملي Factorial Validity، أما دلالات

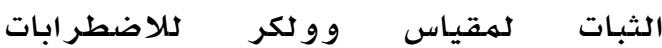

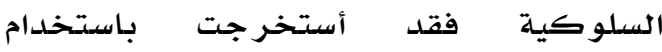

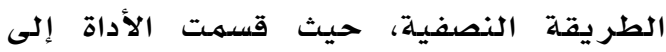
جز أين متكافئين، تم حساب معامل الارتباط

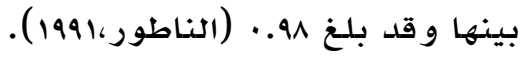

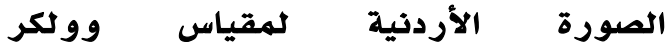
للاضطرابات السلوكية: قامت الناطور

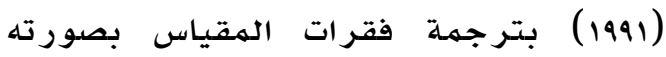

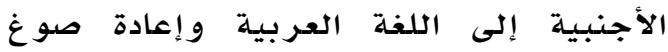
الفقرات، و عر ضها على ثلاثة متخصصين في علهم النفس والتربية. إذ تم تغيير الفقرات

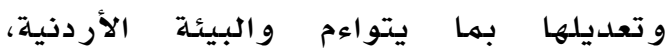
و استبدالها بفقرات جديدة مـائممة، وإعادة عرضها بعد التعديل على المتخصصين الذين

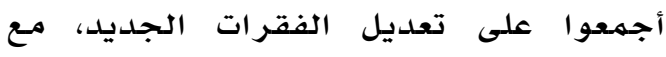

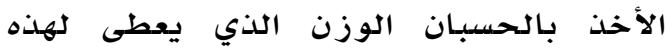
الفقر ات.

دلالات صدق وثبات الصورة الأردنية لمقياس وولكر لاضطرابات السلوكية: تمثلت دلالات صدق مقياس ووولكر للاضطرابات السلوكية بصورته الأردنية بحسب ما أشارت

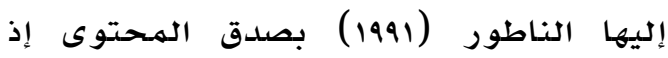

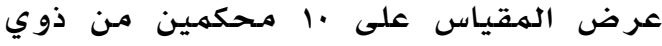

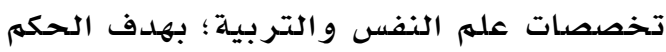

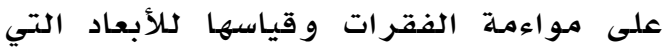

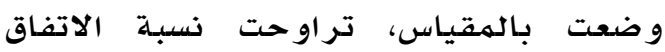
المحكمين •^\% فما فوق. كما تمثلت دلالات صدق الهقياس أيضا بصدق البناء؛ إذ تم

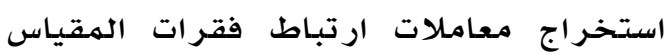


و الدرجة الكلية للمقياس، وذلك بعد تطبيق المقياس على عينة استطلاعية من خارج عينة

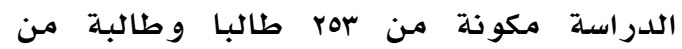

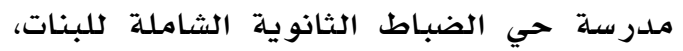

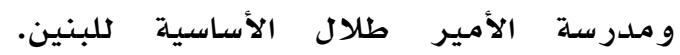

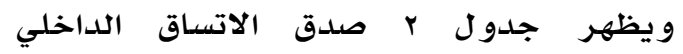
لمقياس التنمـر الإلكترو جلمول.

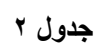

معاملات ارتباط بيرسون بين درجات كل عبارة والارجة الكلية للمقياس التنمر الإكتروني

\begin{tabular}{|c|c|c|c|c|c|}
\hline معامل الارنباط & 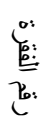 & بيرسون معامل & 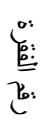 & معامل الارتباط & : \\
\hline$* * \cdot, \wedge \uparrow$ & Ir & $* * \cdot, \wedge r$ & V & $* *,, 9 \leq$ & 1 \\
\hline$* * \cdot, \wedge$ & $1 \leq$ & $* * \cdot, \wedge \varepsilon$ & $\wedge$ & $* *, \wedge \Lambda$ & $r$ \\
\hline$* * \cdot, \wedge r$ & 10 & $* * \cdot, \wedge r$ & 9 & $* * \cdot, \vee q$ & r \\
\hline$* *, 90$ & 17 & $* *, \wedge \varepsilon$ & 1. & $* *,, V Y$ & $\varepsilon$ \\
\hline$* * \cdot, \wedge)$ & IV & $* *,, V V$ & 11 & $* *,, \vee\urcorner$ & 0 \\
\hline$* * \cdot$, , $\vee$ & 11 & **., & IT & $* *, 90$ & 7 \\
\hline
\end{tabular}

يظهر جلدول r أن معاملات ارتباط فقرات مقياس التنهر الإلكتروني بالدول بالدرجة الكلية

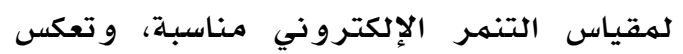

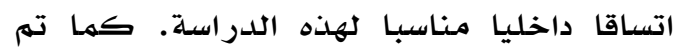
التأكد من ثبات مقياس التنهمر الإلكتروني التياه

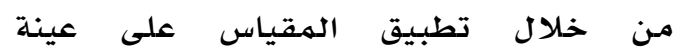

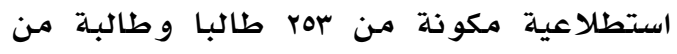

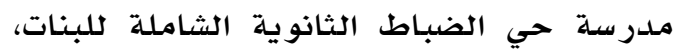

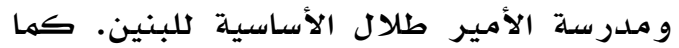
تم حساب معادلة ألفا كرونباخ، حيث بلغ مئن ثبات الهقياس rیر, · و هي درجة ثبات مناسبة.

\section{المعالجة الاحصائية}

كلإجابة عن أسئلة الدراسـة قام الباحثون بالمعالجات الإحصائية اللآتية:

المتوسطات الحسابية والانحر افات

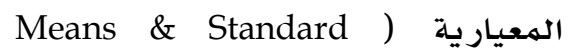
Deviation )، لحساب استجابات أفراد

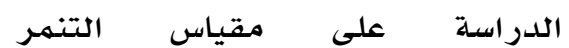
الإلكتر ووني.

اختبار ت (t-test) لقياس الفروق في

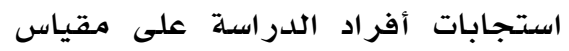
التنهر الإلكترووني تبعا للجنس.
الأردنيين، من خلال إجر اء ما يأتي:

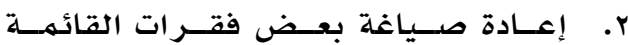

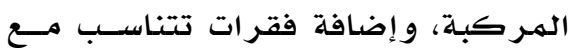

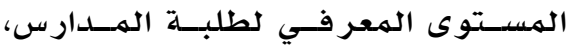

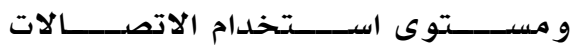

الإلكترو نية لديهم.

r. بناء المقياس بصورته الأو لية على شكل

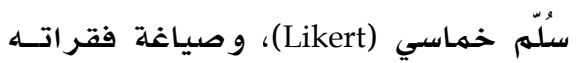
بطريقة التقرير الذاتي.

ع. التحقق من صدق المقياس وثباته.

و للتحقق من صدق مقياس التنمـر الإلكتروني جرى عرضه بصور ته الأو لية على ·1 محككمين من ذوي التخصص و الخبرة في مـجال الإرشاد

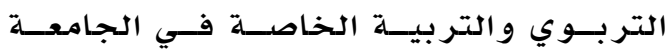

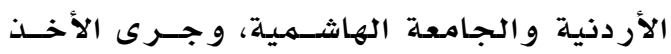

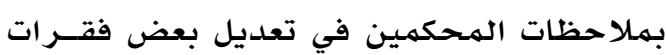
المقياس، حيث تكوّن الهقياس بصور تهله النهائية

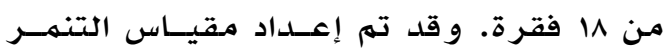

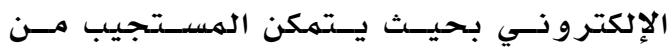

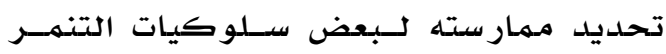

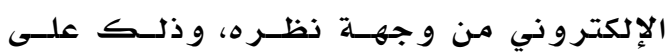

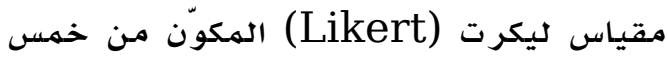

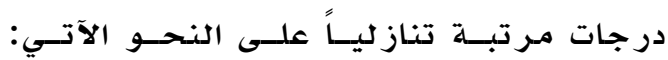
(أوافق بشــدة = ه درجــات)، و (أوافـق = درجات)، و (محايد = ب درجات درات)، و (أعارض

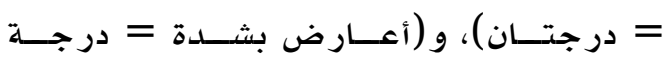
و احدة).

كما تم استخدام القاعدة الرياضية المتمثثلة

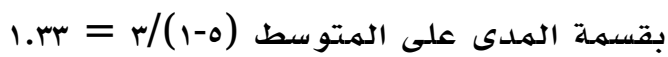

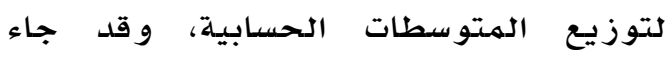
التدريج على النحو التالي: أو لا: (.., (-r,r, ) درجة قليلة. ثانيا: (๕),r-r, ثالثا: (ی,r-., (ه) درجة كبيرة. وللتأكد من الاتساق الداخلي لمقياس التتهمر

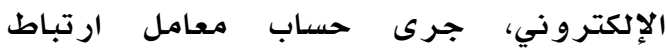
بيرسون (Pearson) بين درجات جلات كل فقرة 
بتقدير درجة كبيرة، وأن جميع فقرات

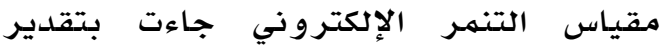

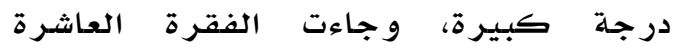
"أنتحل شخصية بعض الطلبة لأشوه سهعتهم وهيره

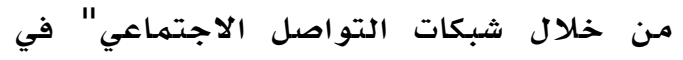

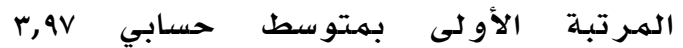

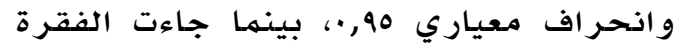

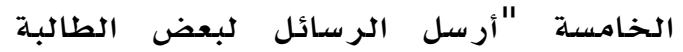

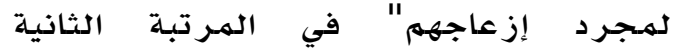

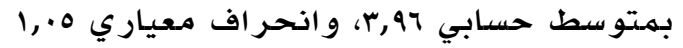
و تر اوحت الهتوسطات الحسابية لبقية فقرات المقياس بين 90,rالفقرة الخامسة عشر "أتدرب على استخدام و سـائل الاتصالات الحديثة لاستخدامها بههارة في إيذاء بعض الطلبـة" في الهـرتبـة الأخيرة

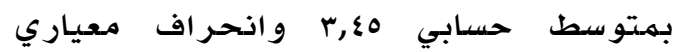
$\therefore, M$

و تعزى هذه النتيجة إلى أن الطلبة

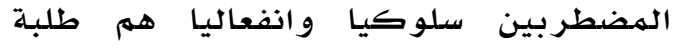
يقعون تحت ضغط انفعالات أكبر من من أقر انهم، مـما يجعلهم يلجأون لشبكات

One Way ) تحليل التباين الأحادي test） واختبار (ANOVA (Scheffe لقياس الفروق في استجابات أفراد الدراسة على مقياس التنهـر الإلكترو ني تبعا للعمر . لمرى

نتائج الدراسة ومناقشتها أولا: نتائج السؤال الأول الذي ينص على "ما مستوى التتمر الإلكتروني للدى الطلبة المضطربين سلوكيا وانفعاليا في مدينة

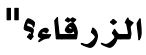

لالإجابة عن هذا السؤال تم حساب المتوسطات الحسـابية والانحر افات الهميارية لأفراد الدراسة الذين يعانون من اضطرابات سلوكية وانفعالية على مقياس التنهر الإلكتروني، وقد تم ترتيب الفقرات تنازليا حسب المتوسط الحسابي كما يتضح في

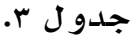

يتبين من جدول ب أن المتوسط الحسابي

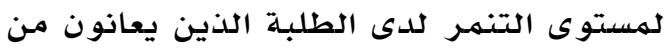

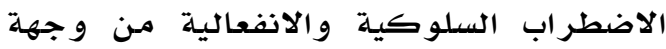

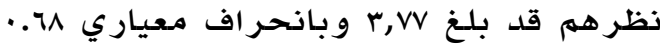

جدول ب

المتوسطات الحسابية والاتحر افات المعيارية لفقرات مقياس التنمر الإكتروني

\begin{tabular}{|c|c|c|c|c|c|}
\hline التقدير & 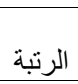 & الالإنحر اف & الحسابي & الفقرة & رقام \\
\hline 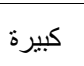 & 1 & $\cdot, 90$ & r,qv & أنتحل شخصية بعض الطلبة لأشوه سمعته من خلال شبكات التواصل & 1. \\
\hline كبيرة & r & 1,0 & ५,१५ & أرسل الرسّائل لبعض الطلبة لهجرد إزعاجهم. & ○ \\
\hline كبيرة & r & 1,4 & r, ,90 & أرسل رسائل و أنشر مو اد حول طالب يمتلك معلومات حساسة وسرية أو حرجة. & 11 \\
\hline كبيرة & $\varepsilon$ & 1,11 & r, , & أكرر بعض الرسائل الإلكترونية بشكل كبير وملح لكي أحصل على رد. & $\varepsilon$ \\
\hline كبيرة & $\circ$ & $\cdot, 9 \varepsilon$ & ५, १६ & أرسل رسائل تتضمن ألفاظا سوقية موجهة نحو بعض الطلبة على الإنترنت. & r \\
\hline كبيرة & 7 & $\cdot 9 \wedge$ & $r, \wedge$ & أستخدم الصور و الأفلام للضرر بسمعة الآخرين. & ir \\
\hline كبيرة & $\mathrm{v}$ & $\cdot 94$ & r,人 & أرسل رسائل إلكترونية تعبر عن غضبي لبعض الطلبة. & 1 \\
\hline كبيرة & $\wedge$ & 1,10 & r,Ar & أعيد إرسال بعض الرسائل الإلكترونية آلّمينة لبعض الطلبة. & r \\
\hline كبيرة & 9 & $\cdot 97$ & r,Ar & أرسل أو أنشر رسائل الكترونية كاذبة تؤذي بعض الطلبة. & $\checkmark$ \\
\hline كبيرة & 1. & 1,11 & r,vq & أتعرض للآخرين بالمضايقة و التهديد بالأذى. & 7 \\
\hline كبيرة & 11 & $1, \cdot 1$ & r, vo & أنظاهر بأني شخص آخر لأرسل رسائل تضر ببعض الطلبة. & 9 \\
\hline 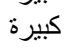 & ir & $\cdot, 10$ & $r, 79$ & أستخدم الصور و الأفلام للضرر بسمعة الآخرين. & ir \\
\hline كبيرة & r & $\cdot, \wedge \wedge$ & $r, 74$ & أحظر بعض الطلبة عن التو اصل مع مجمو عتي لأن ذلك بستفز هم. & 17 \\
\hline كبيرة & $1 \leq$ & $1, \cdot 7$ & $r, \pi$ & أعتمل على تشويه سمعة بعض الطلبة لفظّيا من خلال شبة & $\wedge$ \\
\hline كبيرة & 10 & $1, \cdot 1$ & rוt & أحب معرفة الصفحات الثخصية لبعض الطلبة لاستخدامها مستقبلا في تهديدهم. & in \\
\hline كبيرة & 17 & $\cdot 94$ & r,Tr & أهدد من لا يعجب بمنشور اتي على شبكات التو اصل الاجتماعي. & iv \\
\hline كبيرة & iv & $\cdot, \wedge 1$ & r,00 & سمعة بعض الطلبة. باستخدام وسائل الاتصال الحديثة لآستخمها للتهديد أو تشويه & $1 \leq$ \\
\hline كبيرة & 11 & $\cdot, \wedge \wedge$ & $r, \leqslant 0$ & بعض الطدبة. على استخدام وسائل الاتصالات الحديثة لاستخدامها بمهارة في إيذاء & 10 \\
\hline كبيرة & & $\cdot, \uparrow$ & r, YV & 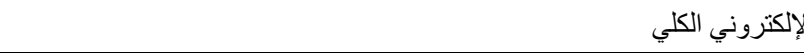 & 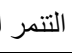 \\
\hline
\end{tabular}


عن الدلاكة الإحصائية للفروق بين

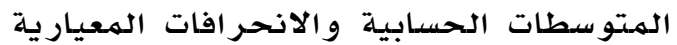
لاستجابات أفر اد الدراسـة على مقياس التتـمر

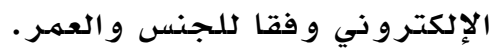

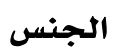
تم استخدام اختبار ت ت (t-test) لعينتين مستقلتين للتعرف على دلالة ما قد يوجد من

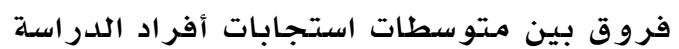
على مقياس التتهمر الإلكترووني وفقا للجنس، لـوسل

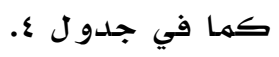

يتبين من جدول ع وجود فروق ذات دلالة

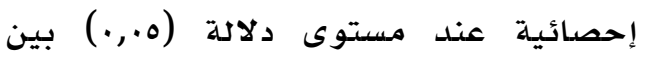

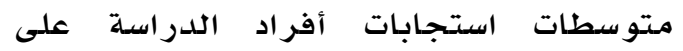

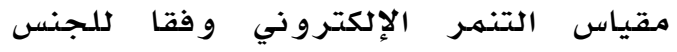

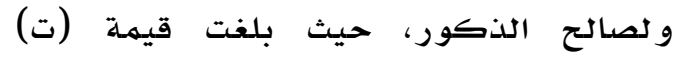
(11,^£ $)$ قيمهة دالة إحصائيا.

وتعزى هذه النتيجة إلى أن الذكور أكثر

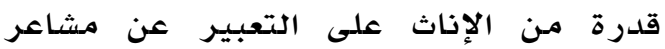

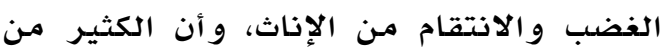
الآباء في العالهم العربي وفقا للتقاليد السـائدة

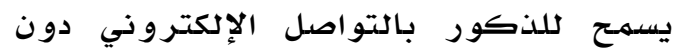
ضوابط، في حين يضعون الكثير الضوابط

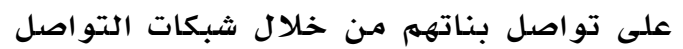
الاجتهاعي. كما أن الذكور يتيحون للكثير

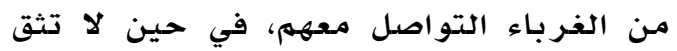
كثير من الإناث بالغرباء وتحظر الغراء الغرباء مـن الولوج لصفحاتهن الخاصدة في مواقع

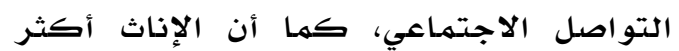

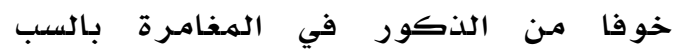
و الشتم و التهجم على الآخرين من خلاتل

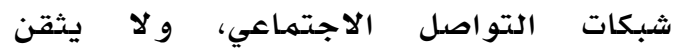
بضمانات الخصوصية والأمان في شبكات
التواصل الاجتماعي لتفريغ لاقاتهم الانفعالية الزائدة. كما أن وسائل الاتصالات الحديثة تسهمح لهم بالتخفي، وتجعلهم

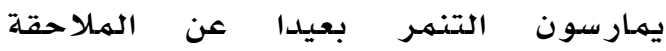

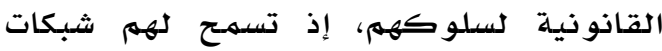
التواصل الاجتماعي بالتواصل دون التحقل التحق

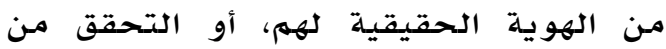

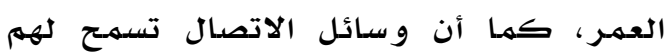
بالرد و مـمارسة التنمر بعيدا عن الطرف الآخر الذي يمكن أن ينتقم مباشرة لو حدث أند

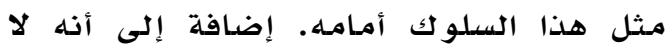
تتوفر للدى الطلبة خبرات عن أية حادثة قضائية حقيقية تشير إلى أن انت انتحال الشخصيات إلكترونيا أو التهجم على شخص إخى الته باسهم مستعار يستوجب إجراءات قانونية مدرسية أو حتى إجراءات قضائية. و وتتفق

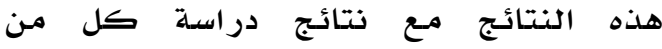

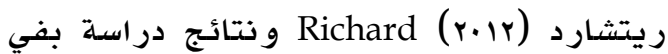
وديان (r..q) (r.quffy and Dianne كشفتا أن التنمـر الإلكتروني في تزايد وأنه و ليد الاتصالات الإلكترونية و أن آثاره تنتقل

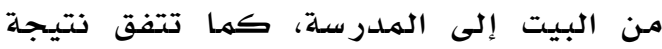

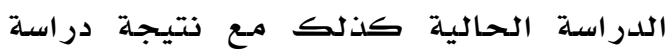
(Swearer et al., 2012)

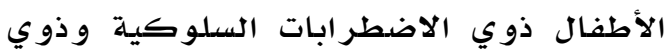

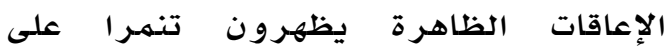
أقر انهم الآخر ين.

ثانيا: نتائج السؤال الثاني والذي ينص على"هل توجد فروق ذات دلاكة إحصائية عند مستوى (0...) في مستوى ملى التنمر الإلكتروني للى الطلبة المضطربين سلوكيا

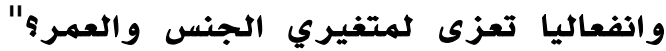
و لإإجابة عن هذا السؤال جرى تطبيق اختبار

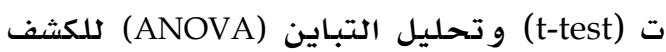

نتائج اختبار (ت) لعينتين مستقلتين للكثف عن الفروق بين متوسطات استجابات أفراد الاراسة على الإسى

\begin{tabular}{|c|c|c|c|c|c|c|}
\hline مستوى الدلالة & ت & روني وقفا للجنس المعياري & المتو سطي الحساهر الإ & العدد & الحiv & المتغنرات \\
\hline \multirow[b]{2}{*}{$\cdot, \cdot$} & \multirow{2}{*}{$11, \wedge \leqslant r$} & $\cdot, \leqslant r 0 \leqslant 1$ & $\varepsilon, 19 V Y$ & 79 & ذكر & \multirow[b]{2}{*}{ 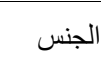 } \\
\hline & & $\cdot, A r \cdot r$ & $r, 1707$ & $\varepsilon \wedge$ & أنثى & \\
\hline
\end{tabular}




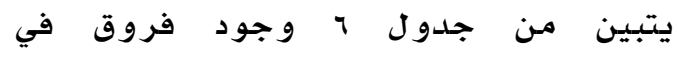

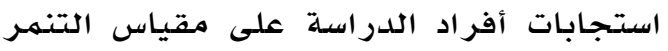

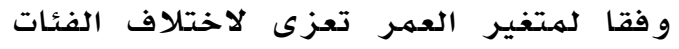
العمرية (من ·1 سنوات إلى با سنة، أكبر

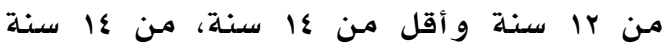

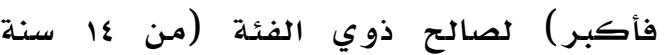
فأكبر)). و تعزى هذه الفروق إلى أن الطلبة

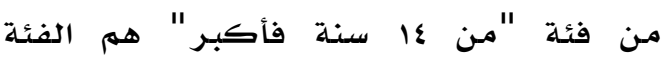
الأكثر امتلاكا للهواتف الذكية، والقدرة

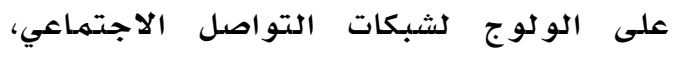

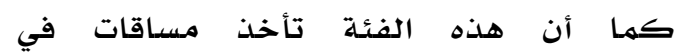
الحاسوب و استخدامات الإنتر نت في المدارس،

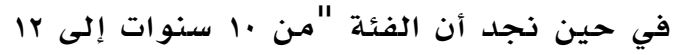

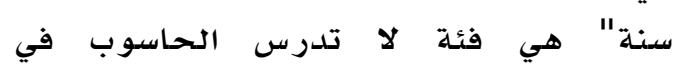

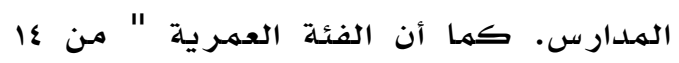

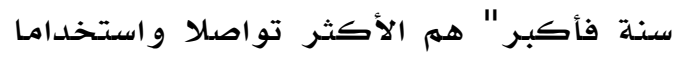

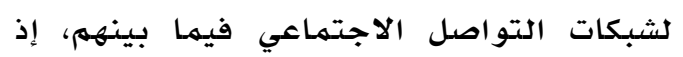

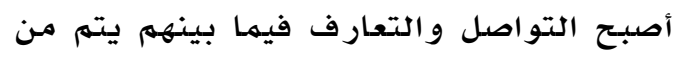

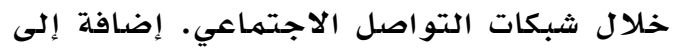

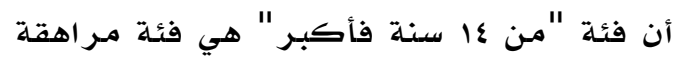

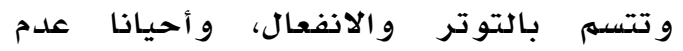

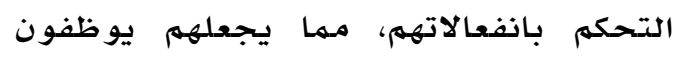

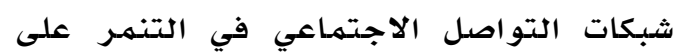

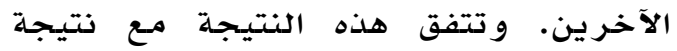

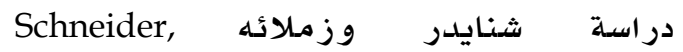
التي (O’Donnell, Stueve \& Coulter,2012)

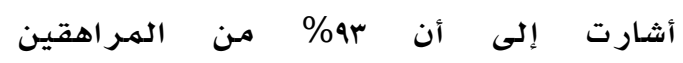

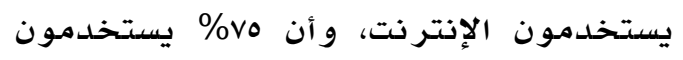

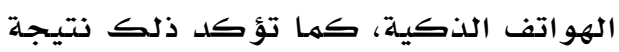

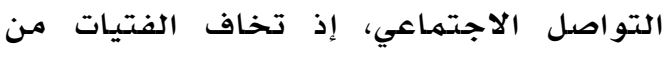
نظرة المجتمـع لهن إن تكشفت بعض مشكلات إدوات

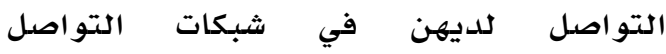

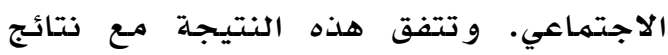
Patricia, et al., ) دراسـة باتريشا و آخرين

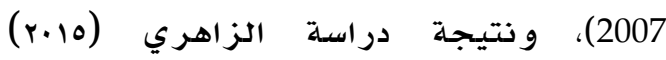
و نتيـجة دراسـة الواكد (10) (10) التي أشسارت نتائج كل منها إلى أن التتهمر الإنكتروني ظاهرة خطيرة وأن مستويات الاستقواء للدى إنى الدي الذكور أعلى من مستوياته لدى لدى الإناث

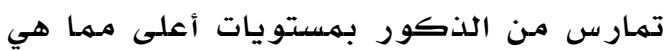
لدى الإناث.

تم استخدام تحليل (ANOVA) للتعرف على دلالة ما قد يوجد من فروق بين متوسطات

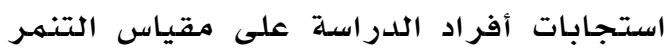

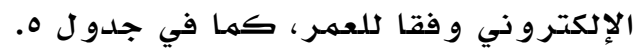
يتبين من جدول ه وجود فروق ذات دلالدة

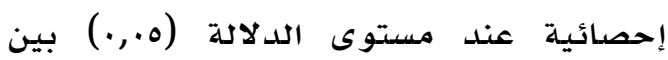

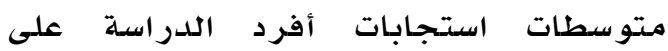

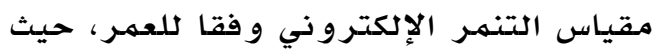

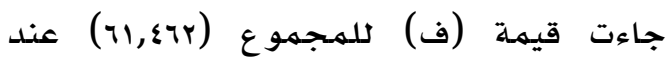

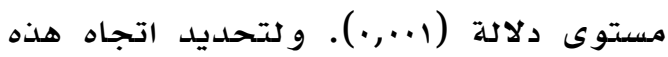

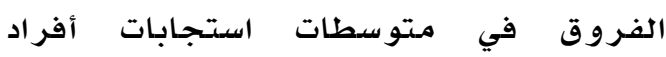
الدراسـة على مقياس التنهـر الإلكترووني، تم

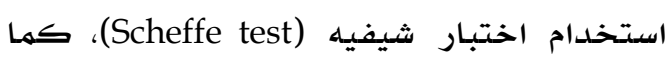

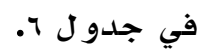

\begin{tabular}{|c|c|c|c|c|c|}
\hline \multicolumn{6}{|c|}{ نتائج اختبار تحليل التباين الأحادي للكثف عن الفروق بين متوسطات استجابات أفراد الدراسة على مقياس التنمر } \\
\hline الدلالة الإحصائية & ف & متوسط المربعات & درجات الحرية & مجموع المربعات & مصادر التباين \\
\hline \multirow{3}{*}{,$\cdots 1$} & \multirow{3}{*}{$T, \sum \pi T$} & \multirow{3}{*}{$\begin{array}{l}14,994 \\
., Y Y \wedge\end{array}$} & $r$ & $r V, 910$ & بين المجموعات \\
\hline & & & $11 \varepsilon$ & ro, $90 \leqslant$ & داخل المجمو عات \\
\hline & & & 117 & or,quq & الكلي \\
\hline
\end{tabular}

جدول 7

نتائج اختبار (شيفيه) البعدي، اتجاه الفروق في متغير العمر لدى أفراد الدراسة

\begin{tabular}{|c|c|c|c|c|c|}
\hline$\mu$ & $r$ & 1 & المتوسط الحسابي & آلعدد & 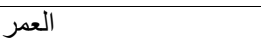 \\
\hline 1,10 & - & - & $r, I V Y$ & Tr & من · ا إلى ז I سنة \\
\hline$\cdot, T V$ & - & - & r,09r & M & أكبر من I I و أقل من ع ا \\
\hline - & $\cdot, T V$ & 1,10 & $\sum, Y \backslash \vee T$ & $0 \leqslant$ & ع ( سنة فأكبر \\
\hline
\end{tabular}




$$
\text { المراجع }
$$

\section{References}

أبو الديار، مسعد (rا.r). التنمر لدى ذوي

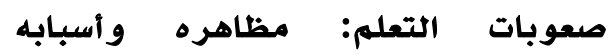
و علاجه. (طץ)، الكويت: مكتبة الكويت واهيت

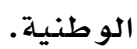

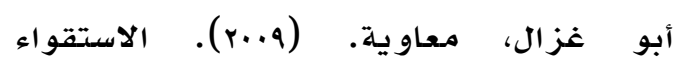

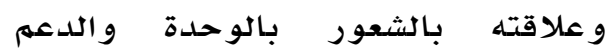
الاجتماعي. المجلة الأردنية في العلوم

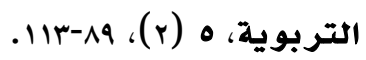
انجشايري، حفيظة. (10.r). الاضطرابات

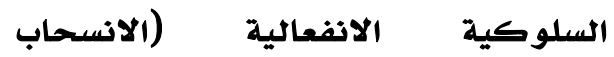

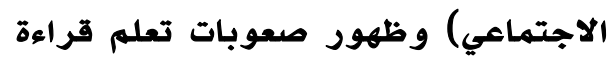

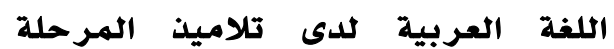
الابتدائية الذين تتراوح أعمارهم ما بين

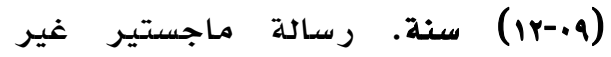

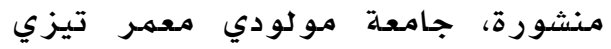

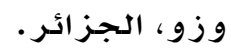

بني يونس، محمد (17.r). الحالات الانفعالية

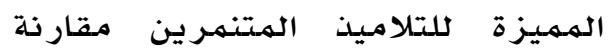
بالتلاميذ غير المتنمرين. مجلة إتحاد

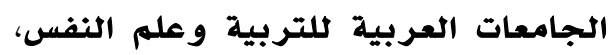
1

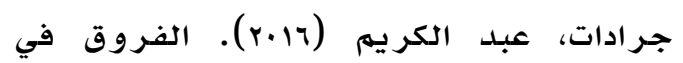

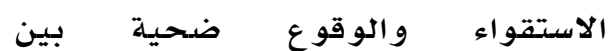

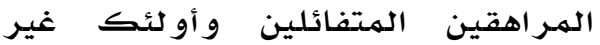

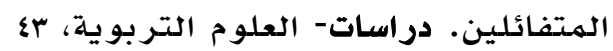
.07.-0६9 9 (1)

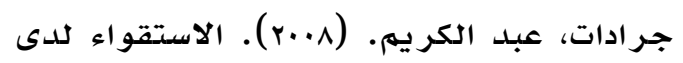
طلبة المدارس الأساسية: انتشاره و العوامل المرتبطة به. المجلة الأردنية

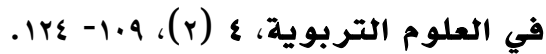
الخطيسب، جهـال (11.r). تعـديل السـلوك كونك الإنساني. عمان: دار الفكر.

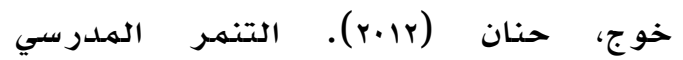

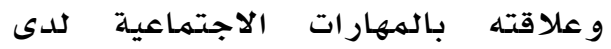

تلاميذ المرحلة الابتدائية بمدينة جدة الاجتهاعة لاعلة
دراسة لينهارت و مادن و ماكجيل وسميث Lenhart, Madden, Macgill, \& Smith, )

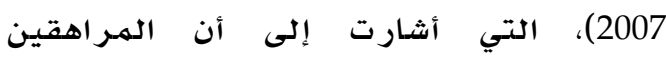
يستخدمون الإنترنت بشكل يومي، مما يشير الفير الفران إلى أن هنالك مجال كبير للتنمر الإلكتروني الإنترني بينهم.

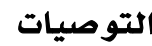
في ضوء نتائج الدراسة يوصي الباحثون بالتو صيات الآتية:

1. تبني منهج إرشاد توعوي لتوجيه

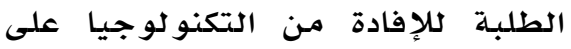

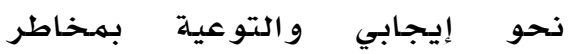

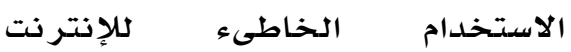

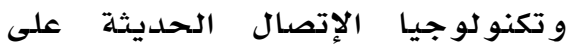

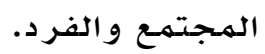
r. إجراء مزيد من الدراسات لمعرفة مستوى التنمر الإلكتروني و أشكاله وأسبابه في البيئة الأردنية والعربية العبية في ضوء متغيرات لهم تشملها الدراسة العابة

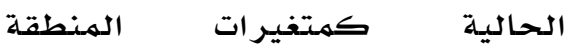

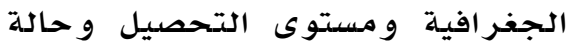

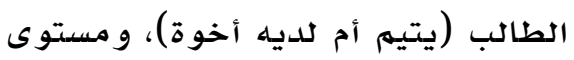

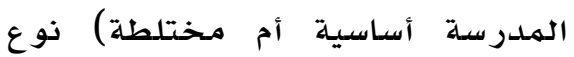

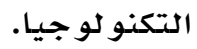
r. إشراك الطلبة في أنشطة وبرامج

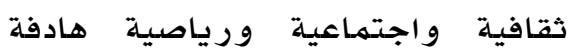
لمنحهم فرص واجتهاعية الإتصال الإجتماعية الإيجابي البناء.

ع. إشراك الأسر في اجتماعات وقرارات مدرسية لمواجهة التنمر الإلكتروني

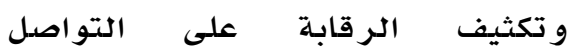
الإجتماعي بين الطلبة.

0. العمل على تطوير برامج مدررسية

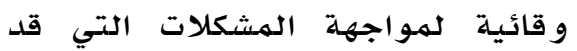
يفرضها التنمر الإلكتروني بين طلبة البة التئ

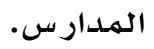




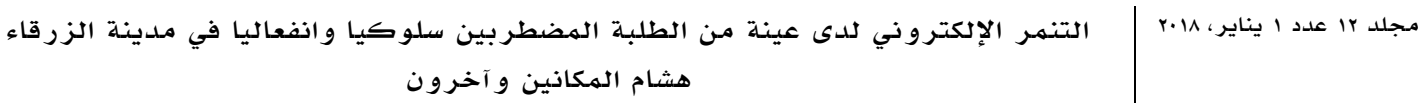

Al-Zahrani, A. M. (2015). Cyberbullying among Saudi's higher-education students: Implications for educators and policymakers. World Journal of Education, 5 (3), 15- 32.

Anderson, N. (2007). A rough week for free speech: Retrieved November 12, 2008

fromhttp:/ / arstechnica.com/ news.ars /post/20070211-8812.html

Bery, K., \& Hunt, J. (2009). Evaluation of intervention program for anxious adolescent boys who are bullied at school. Journal of Adolescent Health, 45(4), 376-382.

Buffy, F \& Dianne, O. (2009). Cyberbullying: A literature Review. Paper presented at the Annual Meeting of the Louisiana Education Research Association Lafayette.

Delfabbro, P., Winefield, T., Trainor, S., Dollard, M., Anderson, S., Metzerm, J. \& Hammarstrom, A. (2006). Peer and teacher bullying/victimization of South Australian secondary school students: prevalence and psychological profiles. British Journal of Educational Psychology, 79(1), 71-90.

Eslea, M., Menesini, E., Morita, Y., O'Moore, M., Moramerchan, J., Pereira, B. \& Smith, P. (2004). Friendship and loneliness among bullies and victims: data from seven countries. Aggressive Behavior, 30(1),7183.

Hallahan, D., Kauffman,.M., \& Pullen, P. (2009). Exceptional learners: Introduction to special education. (11th ed.). Boston: Allyn \& Bacon.

Hinduja, S., \& Patchin, J. (2008). Bullying beyond the schoolyard: preventing and responding to cyberbullying. California: Corwin Press.

Juvonen, J., \& Gross, E. (2008). Extending the school grounds? Bullying experiences in cyberspace. The Journal of School Health, 78(9), 496-505.

Kauffman, J, M., \& Landrum, T. J. (2009). Characteristics of emotional and behavioral disorders of children and youth (9th ed.). Boston: Pearson/ Merril.

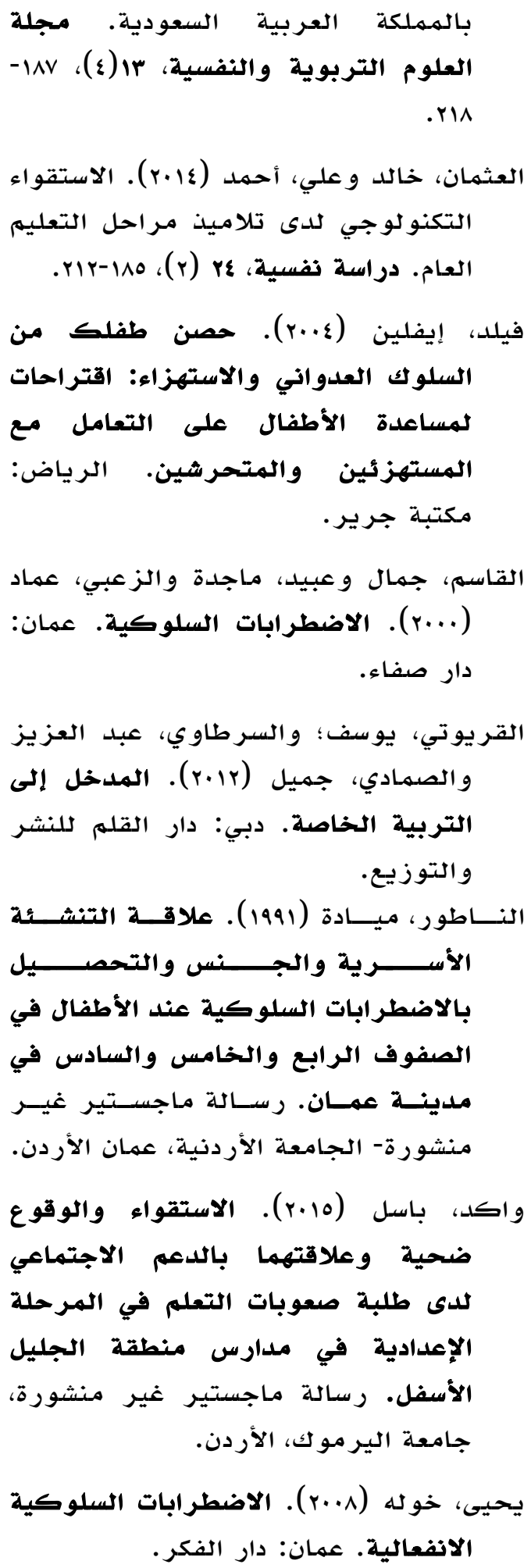


Kowalski, R., \& Limber, S. (2007). Electronic bullying among middle School Students. Adolescence Health, 41(6), S22-S30.

Kowalskia, M., \& Fedina, C .(2011). Cyber Bullying in ADHD and Asperger Syndrome Populations, Research in Autism Spectrum Disorders, 5(3). 1201-1208.

Lenhart, A., Madden, M., Macgill, A., \& Smith, A. (2007). Teens and social media: The use of social media gains a greater foothold in teen life as they embrace the conversational mature of interactive online media. PEW Internet $\mathcal{E}$ American Life Project. Retrieved November 15, 2008 from http:/ / www.pewInternet.org /PPF/r/230/report_display.asp

Liang, H., Flisher, A., \& Lombark, C. (2007). Bullying, violence, and risk behavior in South African school student, Child Abuse and Neglect, 31(2), 161-171.

Litz, E. (2005). An analysis of bullying behaviors at E.B. Stanley middle school in Abingdon, Virginia, Unpublished Doctoral Dissertation, East Tennessee State University.

Patricia, A., \& Robin, K. \& Susan, L. (2007). Students' perspectives on cyber bullying. Journal of Adolescent Health, 41 (2007), 259-260.

Richard, D. (2012). Bullying and Cyberbullying: History, statistics, law, prevention and analysis. The Elon Journal, 3(1), 32-67.

Robin, K., \& Susan, L. (2007). Electronic bullying among middle school students. Journal of Adolescent Health, 41 (2007), 22-30.

Schneider, S. O'Donnell, L. Stueve, A \& Coulter, R. (2012). Cyberbullying, school bullying, and psychological distress: A regional census of high school students. American Journal Public Health. 102(1), 171-177.

Swearer, S. M., Wang, C., Maag, J. W., Siebecker, A. B. \& Frerichs, L.J. (2012). Understanding the bullying dynamic among students in special and general education. Journal of School Psychology, 50(4), 503-520.

Trolley, B., Hanel, C., \& Shields, L. (2006). Demystifying $\mathcal{E}$ deescalating cyber bullying in the schools: A resource guide for counselors, educators and parents. Booklocker.com, Inc.

Wang, R., \& Nansel T. (2009). School bullying among adolescents in the United States: physical, verbal, relational, and cyber. Journal of Adolescent Health. 45(4), 368-375.

Williams K., \& Guerra, N. (2007). Prevalence and predictors of Internet bullying. Journal of Adolescent Health, 41(1), 14 